\title{
EFFECTS OF VITAMIN NUTRITION ON THE
} IMMUNE RESPONSE OF HATCHERY-REARED SALMONIDS

Annual Report 1987

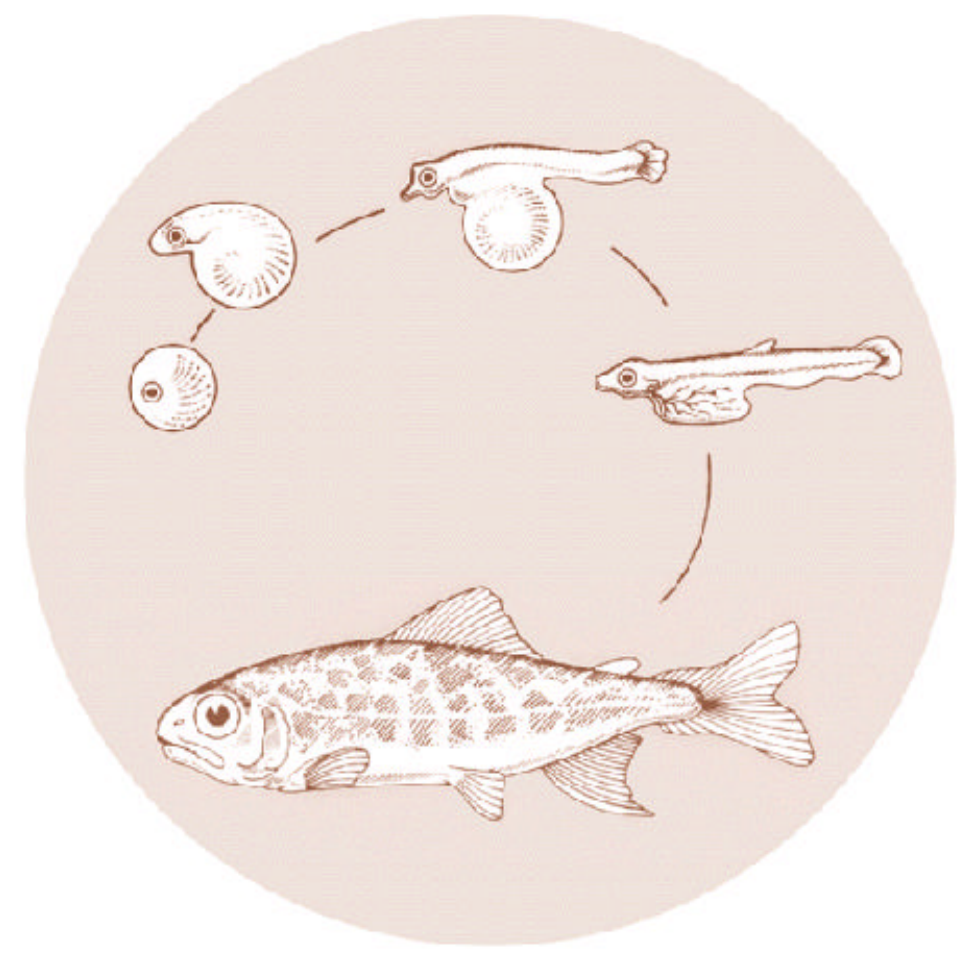

DOE/BP-18010-1 
This report was funded by the Bonneville Power Administration (BPA), U.S. Department of Energy, as part of BPA's program to protect, mitigate, and enhance fish and wildlife affected by the development and operation of hydroelectric facilities on the Columbia River and its tributaries. The views of this report are the author's and do not necessarily represent the views of BPA.

This document should be cited as follows:

Leith, Dave, Mark Newman - Abernathy Salmon Culture Technology Center, Dr. Stephen Kaattari, Nancy Holland, Jenefer Dekoning - Department of Microbiology, OSU, Effects Of Vitamin Nutrition On The Immune Response Of

Hatchery-Reared Salmonids, Annual Report Fy 1987, Report to Bonneville Power Administration, Contract No.

1984BP18010, Project No. 198404500, 77 electronic pages (BPA Report DOE/BP-18010-1)

This report and other BPA Fish and Wildlife Publications are available on the Internet at:

\section{http://www.efw.bpa.gov/cgi-bin/efw/FW/publications.cgi}

For other information on electronic documents or other printed media, contact or write to:

Bonneville Power Administration

Environment, Fish and Wildlife Division

P.O. Box 3621

905 N.E. 11th Avenue

Portland, OR 97208-3621

Please include title, author, and DOE/BP number in the request. 
EFFECTS OF VITAMIN NUTRITION ON THE IMMUNE RESPONSE

$\mathrm{OF}$

HATCHERY-REARED SALMONIDS

ANNUAL REPORT FY 1987

BY

Dave Leith, Project Leader

Mark Newman, Project Biologist

Abernathy Salmon Culture Technology Center

Longview, WA 98632

and

Dr. Stephen Kaattari, Project Leader

Ms. Nancy Holland, Research Assistant

Ms. Jenefer Dekoning, Research Assistant

Department of Microbiology

Oregon State University

Corvallis, OR 97331

Prepared For

Dr. Jeffrey C. Gislason, Project Officer Bonneville Power Administration

Division of Fish and Wildlife

P.O. Box 3621

Portland, OR 97208

Project No. 84-45 and 84-945

Agreement No. DE-AI79-84BP18010 and DE-AI79-84BP18007

August 1987 
The Abernathy Salmon Culture Technology Center (A.S.C.T.C.) and the Department of Microbiology at Oregon State University, with funding from the Bonneville Power Administration, are presently conducting a study on the effects of vitamin nutrition on immunity and disease resistance in chinook salmon (Oncorhynchus tshawptscha) . The long range goal of this project is to define the dietary levels of pyridoxine, folic acid, pantothenic acid, riboflavin, ascorbic acid and vitamin E required to assure maximum resistance to disease.

In the third year of this study we have completed the vitamins riboflavin and pantothenic acid. We first approximated dietary concentrations of these vitamins that would exert the greatest effects on the immune response of salmon. Appropriate vitamin concentration ranges for both vitamins were then tested in a practical (Abernathy diet) and a semi-purified (modified Oregon Test Diet) ration to determine what concentration of vitamin would be required to gain some beneficial effects in a practical feed, and to determine the absolute requirements for immunological sufficiency. Results indicate that there are marginal differences in the immunological parameters tested withrespect to the Vitamin concentrations incorporated into the diets. However, the in vitre and in vive studies indicate that the Abernathy diet can provide greater enhancement of the development of immune responsiveness over that seen with the semi-purifies diet. This may be related to the increased growth rate or feed conversion of fish maintained on the Abernathy diet. 


\section{EXPERINENTAL DESI引iT}

The vitamins chosenfor study were pyridoxine, pantothenic acid, riboflavin, folic acid, Vitamin E, and ascorbic acid. A practical fish feed formulation and a semi-purified test diet are to be compounded to contain incremental amounts of the test vitamins. Each vitamin will be studied singly while dietary levels of all other vitamins are held constant, using the supplementation rates specified in the vitamin packages for each diet. The test diets are fed for up to 24 weeks to duplicate lots of spring chinook juveniles held indoors in circular tanks supplied with well water. During rearing, each lot of fish is weighed biweekly and dead fish are removed and recorded daily to: (1) determine growth rates, (2) calculate food conversion efficiencies, (3) provide population weights on which to base feeding rates, and (4) determine survival rates. Samples of test feeds are analyzed regularly to verify vitamin dietary concentrations, and fish organs will be analyzed for vitamin levels at the termination of each study. Laboratory assays are designed to assess the degree of immune competence in fish from each diet group at regular intervals. The assays will be used to examine in vivo and in vitro parameters of humoral immunity, cellular immunity, and disease resistance. Data concerning growth, food conversion efficiencies, rearing mortality, times to death in disease challenges, and in vitro assays of immune responsiveness are tested by analyses of variance, regression techniques, and ranking to determine significance of differences (5\% level of significance) where applicable and to calculate minimum amount of each vitamin required in the diet to insure maximum functioning of the immune system. 
TABLE OF CONTENTS

Page No,

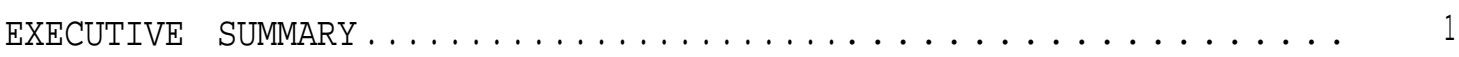

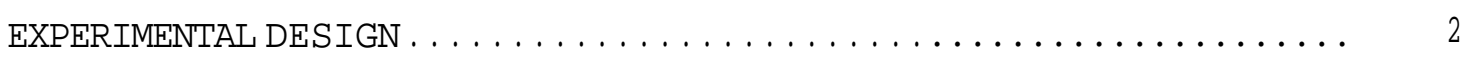

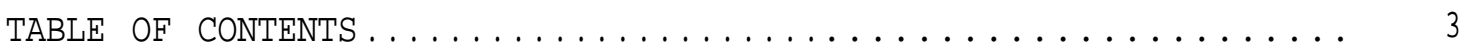

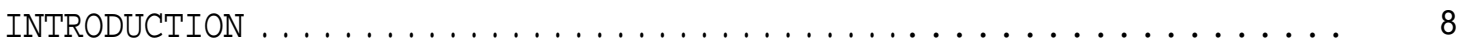

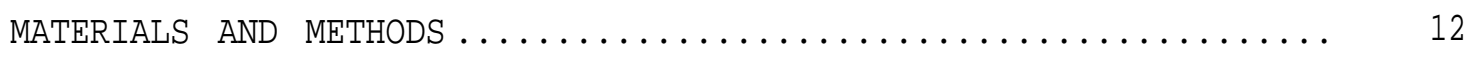

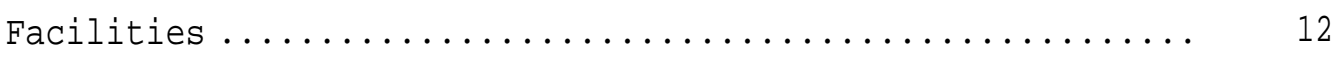

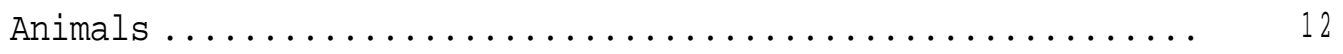

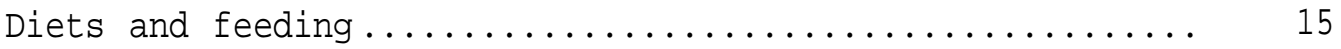

Growth and feed efficiency ..................... 21

Statistical analyses...................... 22

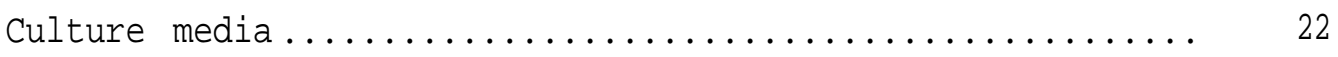

Mitogens and antigens $\ldots \ldots \ldots \ldots \ldots \ldots \ldots \ldots \ldots \ldots \ldots \ldots \ldots \ldots$

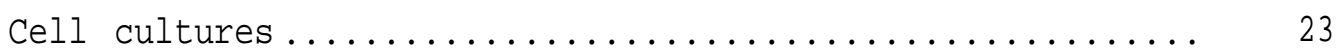

Mitogen assays $\ldots \ldots \ldots \ldots \ldots \ldots \ldots \ldots \ldots \ldots \ldots \ldots \ldots \ldots \ldots \ldots \ldots$

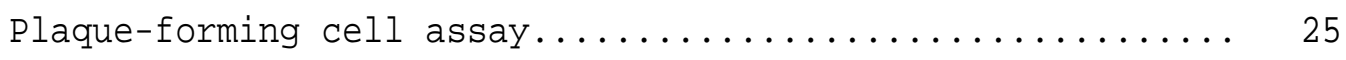

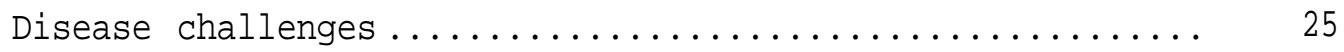

Aeromonas salmonicida $\ldots \ldots \ldots \ldots \ldots \ldots \ldots \ldots \ldots \ldots \ldots$ 
Renibacterium salmoninarum $\ldots \ldots \ldots \ldots \ldots \ldots \ldots \ldots \ldots$

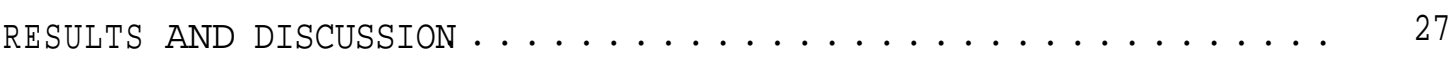

Pyridoxine and folic acid experiments............. 27

Growth and feed efficiences............... 27

Riboflavin and pantothenic acid experiments.......... 27

Growth and feed efficiences ................... 27

Effects of riboflavin on mitogenic responses to Vibrio anguillarum extract $\ldots \ldots \ldots \ldots \ldots \ldots \ldots \ldots \ldots \ldots, 32$

Effect of pantothenic acid concentrations on mitogenic responses to Vibrio anguillarum extract........ 33

Effect of riboflavin concentrations on antibody

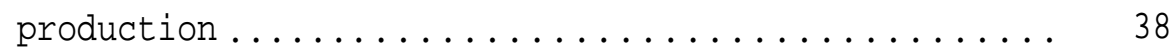

Effect of pantothenic acid concentrations on antibody production $\ldots \ldots \ldots \ldots \ldots \ldots \ldots \ldots \ldots \ldots \ldots \ldots \ldots$

In vitro immune responses as a function of age only... 38

Effect of age and diet group on immune responsiveness. 47

Effect of age and diet group on the increase in immune responsiveness within each replicate tank........ 51

Xeromonas salmonicida challenges.............. 60

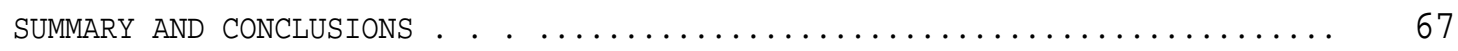

SUMMARY OF EXPENDITURES . . . . . . . . . . . . . . 68

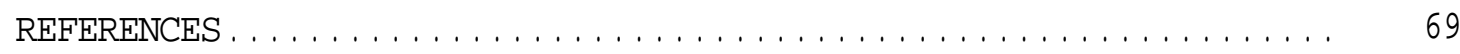




\section{TABLES AND FIGURES}

Table

i. Composition of water supplies.................. 13

2. Compositi'on of Abernathy diet used as a vitamin test ration ........................ 16

3. Composition of Oregon Test diet formula.............. 17

4. Vitamin analysis of formal diets (1987) ............ 18

5. Vitamin analyses of formal diets (1987) ............ 19

6. Specific growth rates and gross feed efficiency (pyridoxine diets) $\ldots \ldots \ldots \ldots \ldots \ldots \ldots \ldots \ldots \ldots$

7. Specific growth rates and gross feed efficiency (folic acid diets) ..................... 29

8. Specific growth rates and gross feed efficiency (riboflavin diets) .................... 30

9. Specific growth rates and gross feed efficiency (pantothenic acid diets)

10. Effect of age on the mitogenic response (net cpm);

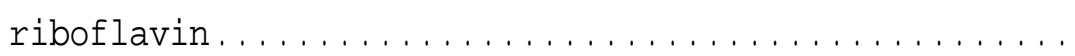

11. Effect of age on the mitogenic response (stim. ind); riboflavin $\ldots \ldots \ldots \ldots \ldots \ldots \ldots \ldots \ldots \ldots \ldots \ldots \ldots \ldots$

12. Effect of age on the mitogenic response (net cpn); pantothenic acid $\ldots \ldots \ldots \ldots \ldots \ldots \ldots \ldots \ldots \ldots \ldots \ldots \ldots \ldots \ldots$

13. Effect of age on the mitogenic response (stim. ind.); 


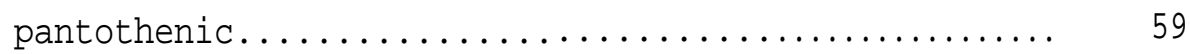

14. Average weights of fish in each riboflavin group...... 61

15. Average weights of fish in each pantothenic acid group. 62

16. Per cent mortality and mean day to death; riboflavin... 65

17. Per cent mortality and mean day to death; pantothenic

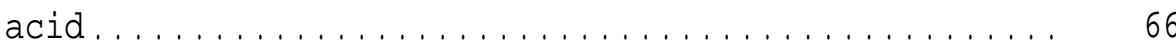

Figure

1. Effect of riboflavin on the mitogenic response to Vibrio anguillarum (net $\mathrm{cpm}$ ) on the first test date....... 34

3. Effect of riboflavin on the nitogenic response to Vibrio anguillarum (stim. ind.) on the first test date.... 35

3. Effect of riboflavin on the mitogenic response to Vibrio anguilarum (net $\mathrm{cpm}$ ) on the second test date...... 36

4. Effect of riboflavin on the mitogenic response to Vibrio anguillarum (stim. ind.) on the second test date.... 37

5. Effect of pantothenic acid on the mitogenic response to Vibrio anguillarum (net cpm) on the first test date.. 39

6. Effect of pantothenic acid on the mitogenic response to Vibrio an guillarum (stim. ind.) on the first test

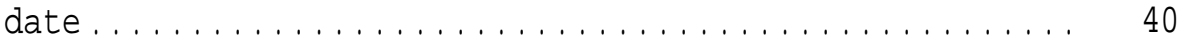

7. Effect ofpantothenic acid onthe mitogcnic response to Vibrio anguillarum (net $\mathrm{cpm}$ ) on the second test date. 41

9. Effect of pantothenic acid on the mitogenic respnse to Vibrio anguillarum (stim. ind.) on the second test date ................................... 42 
9. Effect of riboflavin on the plaque-forming cell response

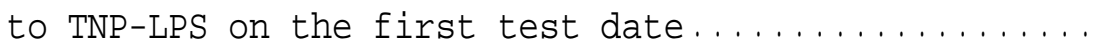

10. Effect of pantothenic acid on the plaque-forming cell

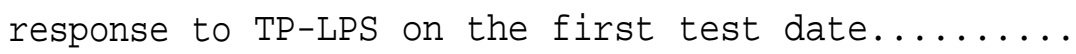

11. Effect of pantothenic acid on the plaque-forming cell response to TP-LPS on the second test date....... 45

12. Effect of age on the mitogenic response (net cpm)..... 47

13. Effect of age on the mitogenic response (stim, ind,)... 48

14. Effect of age on the mitogenic response (back. cpm).... 49

15. Effect of age on the antibody response $(\mathrm{PFC}) \ldots \ldots \ldots \ldots 50$

16. Effect of age and vitamin group on the mitogenic

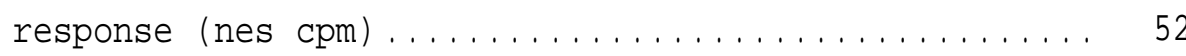

17. Effect of age and vitamin group on the mitogenic

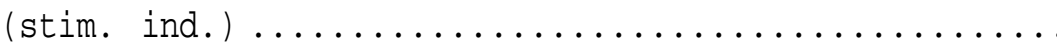

18, Effect of age and vitamin group on the antibody response

19. Aeromonas salmonicida challenges ................ 6 


\section{INTRODUCTIOIN}

The presence of infectious diseases are one of the most important problems affecting the efficiency and economics of salmonid culture. Total mortality experienced during the egg, fry, and fingerling stages of Pacific salmon (Onchorhynchus spp.) culture, for example, normally ranges from 1520\% (Hublo and Jones, 1970). About 50\% of that mortality occurs during the fry and fingerling phases, and most of those deaths are probably attributable to infectious disease. This results in the loss of many millions of fish each year, Additionally, mortality can significantly exceed normal ranges in the event of epizootics resulting in even larger losses during artificial propagation.

Diseases can also produce debilitated fish or survivors which harbor latent infections. Low-grade or latent infections have the potential for significantly reducing the post-release survival of smolts from hatcheries. For example, Sanders (1979) and 3anner et al. (1983) have found that coho salmon (0. kisutch) fingerlings, suffering a low-grade infection of bacterial kidney disease (R. salmoninarum), died at high rates after transfer to seawater. Also, Wedemeyer et al. (1976) reported similar effects when coho smolts had subclinical cases of furunculosis (Aeromonas $\underline{\text { salmonicida) }}$

Considerable research has been done to better understand fish diseases and develop means for their prevention and treatment. That work has concentrated primarily upon identification of agents causing disorders, 
improving diagnostic methods, exploring chemotherapeutic treatments, and developing vaccines. Very little work, however, has been done to determine the relationships among the nutritional state, immunocoapetence, and disease resistance in fish (Bell et al., 1984; Blazer and Wolke, 1984; Hardy, 1979; Durve and Lovell, 1982).

Research with livestock laboratory animals, and humans has provided a large body of information which demonstrates the importance of host nutrition in combating disease. Observations made by pathologists at hatcheries indicate this is also true for fish. For example, Wood (1974) reports case histories in which juvenile coho salmon fed either a dry diet or a moist pellet containing corn gluten meal suffered higher mortality from bacterial kidney disease than did fish receiving the standard moist pellet formula. Wedemeyer and Ross (1973) could not confirm that corn gluten meal increased kidney disease mortality, but fish fed the corn product exhibited a more severe, nonspecific, stress-response to the infection.

Many vitamins hav significant roles in the functioning of immune systems in man and other animals. Several researchers and reviewers (Axelrod and Traketellis, 1964; Beisel, 1582; Blalock et al., 1985; CunninghamRundles, 1982; Debes and Kirksey, 1979; Scott et al., 1976; Wilgus, 1977) have reported that deficiency of pyriodoxine suppresses the immune response in a number of animals. The requirement is dependent, in part, on the amount of dietary protein (Scott et al., 1976), Hardy et al. (1979) found that increased pyriioxine in a high-protein diet rendered chinook salmon fingerlings more resistant to Vibrio anguillarum, but additional pyridoxine

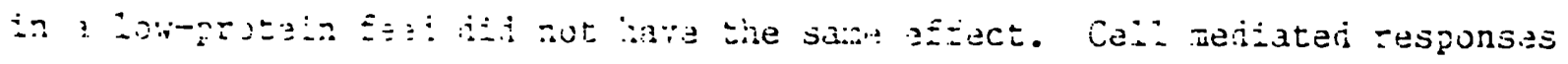


have been demonstrated to be dramatically affected by reduced pyridoxine, as evidenced by depressed mixed lymphocyte reactivity, prolonged allograft survival, and reduced skin hypersensitivity (Axelrod and Traketellis, 1964). Numbers of blood lymphocytes are dramatically reduced, as well as the weight and size of the spleen and thymus during pyridoxine deficiency (Debes and Rirksey, 1979). Antibody formation is decreased as determined by bacterial agglutination and plaque forming cell responses in rats, swine, chickens and humans fed diets deficient in pantothenic acid (Beisel, 1982; Nelson, 1978; Panda and Combs, 1963; Scott et al., 1976), however, that vitamin apparently has little effect on cell mediated immunity. Insufficient amounts of dietary riboflavin have also caused decreased antibody responses to $\underline{\mathbf{S}}$ pullorumin in chicks (Beisel, 1982). Deficiencies of folic acid lead to reduced host resistance to salmonella and impaired humoral and cellular immune function in both man and experimental animals (Beisel, 1982; Cunningham-Bundles, 1982; Scot': et al., 1976; Siddons, 1978). Impaired functioning of phagocytes and reduced response to phytoheaagglutinin have also been observed in vitamin $B_{12}$ deficiency states. Inadequate biotin intake in rats causes a reduced hemagglutinating antibody response to diptheria toxoid, and reduced development of splenic plaque-forming cells after inoculation with sheep red blood cells (Beisel, 1982). The amount of ascorbic acid in the feed has reportedly influenced disease susceptibility in severai animals (Chatterjee, 1978). Durve and Love11 (1982) found that channel catfish (Ictalurus pucctatus) were more resistant to the bacterium Edwardsiella tarda when fed elevated doses of vitamin $\mathrm{C}$ and the effect was more pronounced at lower water temperatures. On the other sand, Bell et al. (1985) had equivocal results when studying the effects of dietary ascorbate on the development of bacterial kidney disease in sockeye salmon (0. nerka). 
The role(s) performed by this vitamin are still unclear and controversial. However, it may play an important part in the normal functioning of phagocytic cells (Beisel, 1982; Cunningham-Rundles, 1982). Two fat soluble vitamins, A and $E_{1}$, have recognized effects on immune systems of other animals. Vitamin A probably influences resistance to infections through its role in maintaining the integrity of the epithelial and mucosal membranes as well as affecting humoral and cell mediated immune responses (Beisel, 1982; Panda1 and Combs, 1963). Vitamin $\mathrm{E}$ has been shown to improve the humoral immune responses of mice, chicks, turkeys, swine, sheep, and guinea pigs when challenged with either nonliving antigens, living bacteria, or live viruses (Beisel, 1982; Colnago et al., 1984; Ellis and Vorhies, 1976; Heinseling et al., 1974; Nockels, 1980). Blazer and Wolke (1984) found that rainbow trout (Salmo gairdneri) showed a significantly reduced humoral immune response and reduction of several non-specifis resistance factors when fed diets deficient in Vitamin $\mathrm{E}$. Since Vitamin Eis an antioxidant which prevents autooxidation of lipids and/or protects the animal from toxic efects of oxidation products (Lee and Sinnhuber, 1972), the amount of lipid in the diet and its degree of rancidity could be imporant factors in the relationship between this vitamin and immunity. Past research to define the quantitative vitamin needs of juvenile salmonids has concentrated primarily on determining requirements for maximum growth and most efficient feed utilization (Halver, 1972; National Academy of Sciences, 1973) without attempts to assess the immunocompetency of test animals. Work is needed to deter-mine the quantities of key vitamins required to insure optimal functioning of immune systems and high resistance to common diseases. 
Facilities. The feeding and rearing phases of the experiments were performed at the Abernathy Salmon Culture Technology Center (SCTC), Longview, Washington. Immunological assays and disease challenges were performed on chinook salmon obtained from Abernathy and housed at the Oregon State University Department of Microbiology and the Fish Disease Laboratory (OSUFDL), Corvallis, Oregon.

During rearing, the fish were held in 1200-liter steel, circular tanks furnished with constant temperature $\left(12^{\circ} \mathrm{C}\right)$ well water. During disease challenges, fish were housed in 30 -liter fiberglass tanks supplied with $12^{\circ} \mathrm{C}$ well water. The compositions of the two water sources are given in Table 1.

The amount of water flowing into each 1200-liter rearing tank was maintained at 12 liters per ninute throughout the studies. The 30 liter tanks used to hold fish during disease challenges received flows of 0.40 liters per minute. Fish population densities ( $\mathrm{kg} /$ inflow/min and $\mathrm{kg} / \mathrm{m}^{3}$ of space) never exceeded the guidelines of Banks et al. (1979).

Illumination of the experimental tanks was provided from fluorescent lights controlled by a photocell system to simulate the natural photoperiod at the latitude of the Abernathy SCIC

Animls. Spring chinook salmon were used as test animals in all experiments. In the pyridoxine/folic acid study they were obtained as eyed eggs which had 
Tabl e 1. Compositi on of uater suppli es.

\begin{tabular}{|c|c|c|c|}
\hline \multirow[b]{2}{*}{ Measur enent } & \multirow[b]{2}{*}{ Uni t } & Whter & \multirow{2}{*}{$\begin{array}{l}\text { Suppl y } \\
\qquad \begin{array}{l}\text { I munol ogi cal } \\
\text { Test i ng }\end{array}\end{array}$} \\
\hline & & $\begin{array}{l}\text { Fi sh } \\
\text { reari ing }\end{array}$ & \\
\hline Total gas sat uration & $\%$ & 100 & 100 \\
\hline $\mathrm{N}_{2}$ sat uration & $\because$ & 99 & $101-103$ \\
\hline $0_{2}$ sat uration & $\%$ & 89 & 91 \\
\hline & & 7.7 & $7.4_{3}$ \\
\hline Conduct i vity $\left(@ 25^{\circ} \mathrm{C}\right.$ ) & unhos/ cm & 244 & $--^{3}$ \\
\hline Al kal i ni ty, t ot al (as $\left.\mathrm{CaCO}_{3}\right)$ & $\mathrm{mg} / \mathrm{l}$ & 76 & -- \\
\hline Hardness, total & $\mathrm{mg} / 1$ & 90 & -- \\
\hline Phosphate, ortho (as $\mathrm{PO}_{4}$ ) & $\mathrm{ng} / \mathrm{l}$ & 0.023 & - \\
\hline Sol i ds, di ssol ved (@ $105^{\circ} \mathrm{C}$ ) & $\mathrm{mg} / \mathrm{l}$ & 180 & 154 \\
\hline Sol i ds, suspended $\left(105^{\circ} \mathrm{C}\right)$ & $\mathrm{mg} / \mathrm{l}$ & 1.2 & $<1$ \\
\hline Ammoni a, tot al (as $\mathrm{NH}_{3}-\mathrm{N}$ ) & $\mathrm{ng} / \mathrm{I}$ & $<0.02$ & $<.002$ \\
\hline $\mathrm{N}$ trate (as $\mathrm{INO}_{3}-\mathrm{N}$ ) & $\mathrm{ng} / \mathrm{I}$ & 0.33 & .97 \\
\hline $\mathrm{N}$ trite (as $\mathrm{NO}_{2}^{-\mathrm{N}}$ ) & $\mathrm{mg} / \mathrm{l}$ & $<.002$ & $<001$ \\
\hline Car bon di oxi de & $\mathrm{mg} / \mathrm{l}$ & 3.8 & $\because$ \\
\hline Chl ori de & $\mathrm{ng} / \mathrm{I}$ & 14 & 22 \\
\hline Cadmi um & $\mathrm{mg} / \mathrm{l}$ & $<.0003$ & -- \\
\hline Cal ci um & $\mathrm{mg} / \mathrm{l}$ & 18 & 17 \\
\hline Cobal t & $\mathrm{mg} / \mathrm{l}$ & co. 13 & $<1.0$ \\
\hline Copper & $n g / I$ & $<0.001$ & .0025 \\
\hline Iron & ngi I & 0.17 & .016 \\
\hline Lead & my/l & 0.005 & ,016 \\
\hline Magnes i urn & $\mathrm{mg} / \mathrm{l}$ & 11 & 8 \\
\hline Manganese & $\mathrm{ng} / \mathrm{I}$ & 0.10 & .01 \\
\hline Mol ybdenum & $\mathrm{ng} / 1$ & $<0.16$ & $<.025$ \\
\hline Potassi um & $n \mathbf{n g} / \mathbf{I}$ & 2.8 & 1.5 \\
\hline Sodi um & $n g / /$ & 15 & 8.8 \\
\hline Zi nc & $n g / I$ & 0.009 & .0015 \\
\hline Sul f ate & $n g / l$ & 19 & -- \\
\hline Tur bi ai ty & JTU & 11 & -- \\
\hline
\end{tabular}

\footnotetext{
1 ADernativ Oregon State Uni versi ty wel I

3 Data not avai I able.
} 
been collected from fish spawned at Carson National Fish Hatchery (NFH) located about 15 miles north of Carson, Washington on the Wind River. Eggs were transferred to the Abernathy Center, cushioned in moist burlap bags, supported in $40 \mathrm{~cm} \times 40 \mathrm{~cm} \times 25 \mathrm{~cm}$ egg baskets in order to prevent physical trauma, Upon arrival at the Abernathy SCTC, the eggs were surface disinfected with an iodophore (Wescodyne or Argentine $)^{1}$ according to the protocol recommended by Wood (1974). The eggs were then placed in incubator trays (Heath Tecna Corp.) supplied with well water.

In the riboflavin/pantothenic acid study, eggs and milt were collected from fish at Carson WFH, and transported separately to Abernathy SCTC in chilled containers. The eggs were fertilized upon arrival at Abernathy SCTC and placed immediately into the Heath incubators.

After hatching and yolk absorption, the resulting fry were stocked in a 1200-liter, steel, circular tanks furnished with well water at 40 liters/minute. In the pyridoxine/folic acid study they were fed ad libitum a proprietary starter formulation (Biodiet-Bioproducts, Warrenton, Oregon) until they reached an average size of $1.6-1.9 \mathrm{~g}$, at which time they were randomly distributed into fiberglass rearing tanks by the following procedure. Groups of ten fish were hand counted into separate baskets until a totai of 300 fish per basket was reached. Each basket was then assigned to a diet. Each diet used in this study, and its replicate, was written on a separate piece of paper. All the pieces ofpaper were then placed into a container, mixed, and removed one at a time and assigned to a basket. Each basket was then assigned to a rearing tank using the same procedure. 
In the riboflavin/pantothenic acid study the fry were fed the same starter diet until they reached approximately two grams, and then fed a dry Abernathy diet until they reached about five grams, at which time they were stocked into the experimental tanks.

Each replicate of each diet was randomly assigned a rearing tank by use of a random numbers table. Groups of ten fish were hand counted into separate, immersed baskets until 150 fish per basket was reached. Then each basket was assigned to a rearing tank by use of a random numbers table. The procedure was repeated once to reach a final stocking density of 300 fish per tank .

Diets and Feeding Both experiments compared the test vitamins at five levels within two diet types: (1) a dry commercial diet (Abernathy - Table 2), and (2) a semi-purified diet (Oregon Test Diet - Table 3).

The pyridoxine/folic acid study compared pyridoxine with a range of $5-88 \mathrm{mg} / \mathrm{Kg}$ dry diet, and folic acid within a range of $2-21 \mathrm{mg} / \mathrm{Kg} \mathrm{dry}$ diet (Table 4).

Riboflavin and pantothe ic acid are currently being tested within the ranges 5-2000 mg/Kg dry diet acd 10-400 mg/Kg dry diet for riboflavin and pantothenic acid, respectively (Table 5) .

The Abernathy Diet was prepared in the same manner in both studies. 
Table 2. Composition of Abernathy Diet used as a vitamin test ration for spring chinook salmon (Oncorhynchus tshawytscha) fingerlings. Immunological study, Abernathy Salmon Culture Technology Center, 1986.

Component Percent

Herring meal, minimum protein

40.57

Dried whey, minimum protein $12 \%$

5.00

Wheat germ meal, minimum protein 23\%

5.00

Wheat standard middlings, minimum protein $15 \%$

26.65

Blood meal, spray dried, minimum protein $80 \%$

10.00

Vitamin premix

1.50

Ascorbic acid

0.10

Choline chloride, 60\% product

0.58

Trace mineral premix

0.10

Herring oil, stabilized with $0.04 \%$ BHA-BHT (1:1)

10.50

100.00

$1 \mathrm{Mg} / \mathrm{kg}$ of diet unless otherwise indicated: riboflavin, 53; niacin, 220; folic acid, 12.7; thiamine, 43; biotin 0.63; B-12, 0.06; vitamin $\mathrm{K}$, 9; inositol, 132; d-panthothenic acid, 106; pyridoxine, 31; vitamin E, 503 IU; vitamin $\mathrm{D}_{3}$, $441 \mathrm{IU}$; and vitamin A, $6614 \mathrm{IU}$.

$2 \mathrm{Mg} / \mathrm{kg}$ of diet: zinc, 75.0; manganese, 20.1; copper, 1.54; and iodine, 10.0. Mineral sources were zinc sulfate, mangenese sulfate, copper sulfate, and potassium iodate. 
Table 3. Composition of the Oregon Test Diet formula (National Academy of Sciences, 1973). Immunological study, Abernathy Salmon Culture Technology Center, 1986.

\begin{tabular}{|c|c|}
\hline Components & $\begin{array}{c}\text { Percentage of Dry Component } \\
\text { Modified Oregon Test } \\
\text { Diet }\end{array}$ \\
\hline Vitamin-free casein & 45.9 \\
\hline Gelatin & 8.1 \\
\hline Dextrin & 15.6 \\
\hline $\begin{array}{l}\text { Carboxy methyl cellulose } \\
\text { alpha-cellulose }\end{array}$ & $\begin{array}{c}1.3 \\
12.129\end{array}$ \\
\hline $\begin{array}{l}\text { alpha-tocopherol }(250 \mathrm{IU} / \mathrm{g}) \\
\text { choline chloride }(99 \%)\end{array}$ & $\begin{array}{l}0.264 \\
0.707\end{array}$ \\
\hline Vitamin premix & 2.0 \\
\hline
\end{tabular}

$\mathbf{a}, \mathbf{b}$ are identical in composition to those described by the National Academy of Science (1973).

Final diet composition: 35\% dry ingredients $65 \%$ water 
Table 4. Vitamin analysis ${ }^{\text {a }}$ of formal diets. Immunological study. Abernathy Salmon Culture Technology Center, 1986.

mg vitamin/kg dry diet

Diet Nominal vitamin level Actual vitamin level n

$$
(\mathrm{X}+\mathrm{SE})
$$

\begin{tabular}{|c|c|c|c|}
\hline $\begin{array}{l}\text { Abernathy } \\
\text { Folic acid }\end{array}$ & $\begin{array}{r}6 \\
10 \\
14 \\
18 \\
22\end{array}$ & $\begin{array}{r}6.1 \pm 0.5 \\
9.9 \pm 0.5 \\
13.1 \pm 1.0 \\
17.3 \pm 1.6 \\
20.6 \pm 1.2\end{array}$ & $\begin{array}{l}5 \\
5 \\
5 \\
5 \\
5\end{array}$ \\
\hline Pyridoxine & $\begin{array}{l}15 \\
35 \\
55 \\
75 \\
95\end{array}$ & $\begin{array}{l}17.1 \pm 3.1 \\
37.1 \pm 5.9 \\
49.3 \pm 6.7 \\
68.7 \pm 2.6 \\
88.4 \pm 5.0\end{array}$ & $\begin{array}{l}5 \\
5 \\
5 \\
5 \\
5\end{array}$ \\
\hline $\begin{array}{l}\text { Semi-purified } \\
\text { Folic acid }\end{array}$ & $\begin{array}{r}2 \\
6 \\
10 \\
14 \\
18\end{array}$ & $\begin{array}{r}2.6 \pm 0.2 \\
6.8 \pm 0.3 \\
11.0 \pm 0.9 \\
14.3 \pm 3.1 \\
19.7 \pm 1.7\end{array}$ & $\begin{array}{l}7 \\
7 \\
7 \\
7 \\
7\end{array}$ \\
\hline Pyridoxine & $\begin{array}{r}5 \\
15 \\
35 \\
55 \\
75\end{array}$ & $\begin{array}{l}5.9 \pm 1.7 \\
17.3 \pm 1.0 \\
41.3 \pm 3.7 \\
64.1 \pm 7.9 \\
80.8 \mp 10.9\end{array}$ & $\begin{array}{l}7 \\
7 \\
7 \\
7 \\
7\end{array}$ \\
\hline
\end{tabular}

a All vitamin analyses were performed by Hazelton Laboratories America, Inc., Madison, Wisconsin. 
Table 5: Vitamin analyses ${ }^{\text {a }}$ of formal diets. Immunological study. Abernathy Salmon Culture Technology Center, 1987.

\begin{tabular}{|c|c|c|c|}
\hline Diet & $\begin{array}{c}\text { Mg vita } \\
\text { Nominal } \\
\text { vitamin level }\end{array}$ & $\begin{array}{l}\text { dry } \frac{\text { diet }}{\text { Actual }} \\
\text { vitamin level }\end{array}$ & $\begin{array}{l}\text { so of } \\
\text { samples }\end{array}$ \\
\hline $\begin{array}{l}\text { Abernathy } \\
\text { Riboflavin }\end{array}$ & $\begin{array}{r}20 \\
65 \\
110 \\
155 \\
200\end{array}$ & $\begin{array}{r}19.4 \pm 2.5 \\
60.8 \pm 4.6 \\
108.3 \pm 10.3 \\
149.5 \pm \quad 6.8 \\
148.5 \pm 31.4\end{array}$ & $\begin{array}{l}5 \\
5 \\
5 \\
5 \\
5\end{array}$ \\
\hline Pantothenic Acid & $\begin{array}{r}40 \\
130 \\
220 \\
310 \\
400\end{array}$ & $\begin{array}{r}40.4 \pm 10.6 \\
129.1 \pm 15.2 \\
204.0 \pm 11.6 \\
273.3 \pm 1.7 \\
366.3 \pm 30.6\end{array}$ & $\begin{array}{l}4 \\
4 \\
4 \\
4 \\
4\end{array}$ \\
\hline $\begin{array}{l}\text { Semipurified } \\
\text { Riboflavin }\end{array}$ & $\begin{array}{r}3 \\
20 \\
\\
65 \\
110 \\
155\end{array}$ & $\begin{array}{r}8.9 \pm 5.2 \\
21.7 \pm 3.7 \\
63.4 \pm 8.0 \\
1 U 4.1 \pm 20.7 \\
147.4 \pm 17.7\end{array}$ & $\begin{array}{l}4 \\
4 \\
4 \\
4 \\
4\end{array}$ \\
\hline Pantothenic Acid & $\begin{array}{r}10 \\
40 \\
130 \\
220 \\
310\end{array}$ & $\begin{array}{r}16.6 \pm 2.9 \\
47.5 \pm 5.7 \\
131.4 \pm 12.8 \\
208.8 \pm 23.1 \\
312.7 \pm 15.4\end{array}$ & $\begin{array}{l}6 \\
2 \\
6 \\
6 \\
6\end{array}$ \\
\hline
\end{tabular}

a

Vitamin analyses were performed by Woodson-Tenent Laboratories, Inc., Memphis, Tennessee; or Hazelton Laboratories America, Inc., Nadison, Wisconsin.

b

Values are: mean + standard error of the mean. 
Meal ingredients were either purchased in a finely ground state or were ground through a hammer mill until they passed entirely through a 20 mesh/inch screen. Components were blended in a paddle mixer and pelletized $12.5 \mathrm{~mm}$ diameter x 2-6 m length) through a small, compaction-type pellet mill without steam conditioning. Sufficient feed for 90 days was prepared at one time and stored at room temperature $\left(22^{\circ} \mathrm{C}\right)$ until fed,

During the pyridoxine/folic acid study, 35 parts dry semi-purified ingredients were mixed with 65 parts water in a dough mixer, then frozen ($40^{\circ} \mathrm{C}$ ) in airtight containers until used. Daily allotments of the purified diets were thawed and extruded through a ricer (3 $\mathrm{mm}$ diameter) from which pellets of desired length $(3-10 \mathrm{~mm})$ were cut.

Preparation of the semi-purified diets for the riboflavin/panthothenic acid study differed somewhat from the previous method. Fifty parts dry ingredients were mixed with an equal weight of water. When cool, the diet wars: passed through a laboratory extruder, where it was compacted and cut into pellets. The pellets were $2.4 \mathrm{~mm}$ in diameter during the first third of the experiment and $3.2 \mathrm{~mm}$ diameter thereafter. They were 2-7 $\mathrm{mm}$ in length throughout the study, Daily rations of pellets were stored in individual containers at $-40^{\circ} \mathrm{C}$. The semi-purified diets in both studies were fed within three weeks of preparation.

Daily feed allotments for all feeds werebased upon a uniform weight of dry food per weight of live fish computed by the methods of Buterbaugh and Willoughby (1967). Feeding was done by hand with frequencies ranging from 
hourly, when the fish were small, to four feedings per day for fingerling fish.

Growth and Feed Efficiency At biweekly intervals, during the rearing phases of tests, each lot of fish was weighed to the nearest gram in a water-filled container. Dead fish were removed from tanks daily and data on their weight and numbers recorded.

Computation of specific growth rates (Mehnken et al., 1980), and gross feed efficiencies (Brett et al., 1969) were done as follows:

Specific growth rates, SGR:

$\log _{\mathbf{e}}$ of weight at end - log, of weight at start $\mathrm{SGR}=$ x 100

days fed 
Gross feed efficiency, GFE:

total fish weight gain in grams

$\mathrm{GFE}=\frac{\text { food offered in grams }}{\text { fo }}$

Statistical Analyses The GFE and SGR data from the pyriodoxine/folic acid study were transformed using an arcsine function, and then analyzed by a twoway ANOVA, and a student-Newman-Keuls Multiple Range Test.

Culture media: Media components were purchased from Whittaker M.A. Bioproducts, Walkersville, MD, unless other noted. Mishell-Dutton holding medium (HM) consisted of $100 \mathrm{ug} / \mathrm{ml}$ gentamicin and $10 \%$ fetal calf serum in RPMI 1640 (Bigco). Mishell-Dutton modified RPMI (RPMI MDM) was used for tissue culture and consisted of RPMI supplemented with: non-essential amino acids, sodium pyruvate, L-glutamine, 10\% fetal calf serum (hybridoma screened), $100 \mathrm{ug} / \mathrm{ml}$ gentamicin, 50 uM 2-mercaptoethanol (MCB, Cincinnati, $\mathrm{OH}$, and the nucleosides, adenosine, uracil, cytosine, and guanine (10 ug/ml, Sigma, St. Louis, MC). The nutritional cocktail was also prepared at previously described (Title and Rittenberg, 1978) and fed daily to the cultures as described below. 
Mitogens and Antigens: The Vibrio angul larum extract was used to induce a mitogenic response and was prepared from v. anguillarum strain SL174 which had been formalin-killed and stored frozen. TrinitrophenylatedLPS (TNP-LPS) was prepared by the method of Jacobs and Morrison (1975). All mitogens and antigens were diluted into tissue culture medium at two times the final desired concentration. Fifty mls thawed packed cells were suspended in ten volumes of $2 \%$ saline and placed in a boiling water bath for two hours. Cells were washed three times in $2 \%$ saiine, centrifuged at $10,000 \mathrm{x} g$ for ten minutes at $4^{\circ} \mathrm{C}$, resuspended in $95 \%$ ethanol, and incubated $: 8$ hours at $37^{\circ} \mathrm{C}$. The cells were then washed two times in acetone, centrifuging at $3,000 \mathrm{x} g$ for ten minutes and dried to a paste overnight at $37^{\circ} \mathrm{C}$. The paste was ground to a fine powder with mortar and pestle and stored at $4^{\circ} \mathrm{C}$. The soluble Vibrio extract used for these studies was prepared by boiling the powder in $\mathrm{PBS}$ at ten $\mathrm{mg} / \mathrm{ml}$ in a boiling water bath for one hour with rrequent agitation. This suspension was then centrifuged at $1,000 \times \mathrm{g}$ to remove particulates and filter sterilized. Protein concentrations were determined by the method of Lowry et al, (1951).

\section{Cell Cultures Fish were sacrificed and their anterior kidneys} aseptically removed and placed in HM. All cultures were prepared under sterile conditions at tha SCTC and then transported in a portable cooler (Koolatron, Batavia,NY) to the laboratory at Oregon State Univeristy, A single cell suspension ofeach organ was obtained by aspiration of the anterior kidney through a $1 \mathrm{ml}$ syringe. The anterior kidney lymphocytes from each fish were tested separately. The resulting cell suspension was incubatied on ice to allow organ fragments to settle. The lymphocytes in the supernatant 
medium were enumerated by the use of a hemoc tometer or coulter counter (CoulterElectronics, Haileah, FL) adjusted for counting salmonid leukocytes. The cell suspension was then adjusted with RPMI MDM to a concentration of $2 \times 10^{7} \mathrm{cells} / \mathrm{ml}$ and held on ice until culture. Aliquots of $0.05 \mathrm{ml}$ of the final cell suspension were added to the wells of a 96-well, flat-bottomed, tissue culture plate (Corning, Corning, NY_containing 0.05 mlof antagen or mitogen. Tissue culture plates were then incubated in plastic culture boxes (C.B.S. Scientific Del Mar, CA) in an atmosphere of 7\% $\mathrm{CO}_{2}$ at. $16^{\circ} \mathrm{C}$. Twenty-four fish were sampled from each tank, and cultures prepared in triplicate.

Mitogen Assays: For the mitogen assays, 50 ul of the cell suspension $\left(1 \times 10^{6}\right.$ cells/ml) were placed in individual wells of a 96-well, flat bottom, tissue culture plate with 50 ul of mitogen or culture medium. The plates were then incubated in gas boxes under $7 \% \mathrm{CO}_{2}$ at $17^{\circ} \mathrm{C}$. Twenty-four hours before harvest each well was pulsed with one uCi of tritiated thymidine (methyl- ${ }^{3}$ H, ICN Biomedicals, Irvine, CA) in 50 ul of RPMI MDM. Cells were harvested with distilled water onto glass fiber filters, with a Skatron ceil harvester (Sterling, VA). The filters were then dried, placed in scintillation vials with cocktail (6g PPO, Sigma, $5 \mathrm{mg}$ ?OPOP, Amersham, Arlington Heights, IL, in one liter toluene, after Etiinger et al., 1976), and counted on a Beckman liquid scintillation counter (EL 3800). Data are reproted as mean counts per minute (cpm) +/- standard error, of triplicate cultures, or as stimulation indices (SI) defined as experimental cpm/control cpm, 


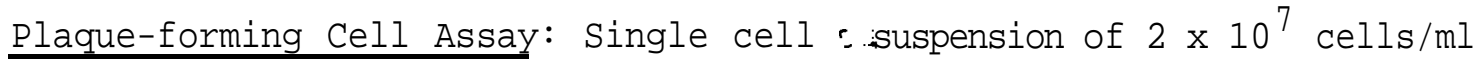
were prepared in RPMI MDM, as described above. For these assays, $0.05 \mathrm{mi}$ aliquots of cells were added to $0.05 \mathrm{ml}$ of the appropriate dilution of antigen in medium Cultures were fed 20 ul of coctail on alternate days until harvest. Cells secreting anti-trinitrophenyl (TNP) antibodies were detected by a modification of the Cunningham plaque assay (Cunningham and Szenberg, 1968). Forty ul of the lymphocyte suspension, 10 ul of a 10\% suspension of TNP-sheep red blood cells (TNP-SRBC; Rittenberg and Pratt, 1969) in modified barbital buffer (MBB), and 10 ul of steelhead serum were mixed, diluted in MBB and deposited into individual wells of a 96-well microtiter palte (Linbro, McLean, VA). The contents of each well was pipetted into a slide chamber, sealed and incubated for $1-2$ hours at $16^{\circ} \mathrm{C}$. Plaques were then enumerated under low power with the aid of a dissecting microscope,

Disease challenges: Fifty fish from each tank at the Abernathy S.C.T.C. were transferred to the Oregon Fish Disease Laboratory in Corvallis for the disease challenges. The fish were transported in 20 gallon containers with 15 gallons of water aerated with oxygen and cooled with block ice. The fish were allowed to acclimate to their new tanks for two days before disease challenge.

Daily mortalities were counted and kidney smears and/or agar plate checks were performed to verify the presence of the disease organism. Mortalities are reported for each tank as percent mortality over the 12-day period and the mean day to death which is calculated as: 
number of mortalities each day $\mathrm{X}$ day post challenge

total number of mortalities over 12 days

Aeromonassalmonicida: Twelve 2-liter flasks with one liter of Brain Heart Infusion broth (BHI; Difco, Detroit, MI) in each were inoculated with ten $\mathrm{ml}$ of a $48 \mathrm{hr}$ A. salmonicida culture grown from a single plate colony. The cultures were gently agitated at $17^{\circ} \mathrm{C}$ for $24 \mathrm{hrs}$. Contents of all 12 flasks were pooled and plate counts made on BHI agar plates. For both challenges, cultures contained approximately $10^{9}$ bacteria/ml as determined by colony counts.

For the immersion challenge, the water level in each tank was drained to approximately two inches above the dorsal. fin of the fish and the water flow was terminated. Five hundred $\mathrm{mls}$ of the A. salmonicida broth culture was added to each tank. Water flow was resumed 20 minutes after the bacteria were added.

Renibacterium salmoninarum These challenge studies were not begun until the current progress report was being prepared, therefore this data will be forthcoming in the the next annual report. 
RESULTS AND DISCUSSION

\section{I. $\quad$ Pyridoxine and Folic Acid Experiments}

Growth and Feed Efficiencies. The growth and feed conversionefficiencies produced by the pyrodoxine and folic acid test diets apear in Tables 6 and 7 . The Abernathy diets consistently produced better growth and feed conversion efficiency $(P<0.05)$ than the semipurified diets at all vitamin levels. This difference occurred for both pyridoxine and folic acid. No effect of vitamin level on either growth or feed confersion efficiency was observed for pyridoxine or folic acid $(\mathrm{P}>0.05)$.

II. Riboflavin and Panthothenic Acid Experiments

Growth and feed Efficiencies. The growth and feed conversion data from the first 83 days of feeding in this year's riboflavin/panthothenic acid study are presented in Tables 8 and 9. The fish fed the Abernathy Diets in which riboflavin was varied all appear to be growing faster and have better

conversion efficiencies, than those fed the semipurified riboflavin diets. There appears to be little effect of riboflavin lieve lon the growth and feed conversion efficiency produced by either diet type.

The panthothenic acid treatmetns differ from the general pattern in that the semi-purified diet-fed are apparently growing as well, if not better, 
Table 6. Specific growth rate and gross feed efficiency of spring chinook (Oncorhynchus tshawytscha) fingerlings fed two diets containing different dietary concentrations of pyridoxine for 167 days. Immunological study. Abernathy Salmon Culture Technology Center, 1986.

\begin{tabular}{|c|c|c|c|}
\hline Diet & $\begin{array}{c}\text { Vitamin level } \\
\text { mg pyridoxine/kg dry diet }\end{array}$ & $\begin{array}{l}\text { Specific } \\
\text { Growth Rate }\end{array}$ & $\begin{array}{c}\text { Gross }^{\text {B,C }} \\
\text { Feed Efficiency }\end{array}$ \\
\hline Abernathy & $\begin{array}{l}17 \\
37 \\
49 \\
69 \\
88\end{array}$ & $\begin{array}{l}1.60 \pm 0.01^{\mathrm{a}} \\
1.58 \pm 0.01^{\mathrm{a}} \\
1.61 \pm 0.01^{\mathrm{a}} \\
1.61 \pm 0.01^{\mathrm{a}} \\
1.59 \pm 0.01^{\mathrm{a}}\end{array}$ & $\begin{array}{l}77.00 \pm 0.30^{c} \\
75.94 \pm 0.80^{\prime} \\
73.56 \pm 1.16^{\prime} \\
73.15 \pm 1.33^{c} \\
72.46 \pm 0.42^{\prime}\end{array}$ \\
\hline Semi-purified & $\begin{array}{r}6 \\
17 \\
41 \\
64 \\
81\end{array}$ & $\begin{array}{l}1.53 \pm 0.00 \mathrm{~b} \\
1.48 \pm 0.01 \mathrm{~b} \\
1.51 \pm 0.01 \mathrm{~b} \\
1.49 \pm 0.02^{\mathrm{b}} \\
1.50 \pm 0.01^{\mathrm{b}}\end{array}$ & $\begin{array}{l}68.81 \pm 0.28 \mathrm{~d} \\
64.30 \pm 0.27 \mathrm{~d} \\
66.21 \pm 2.52 \mathrm{~d} \\
66.26 \pm 1.56 \mathrm{~d} \\
66.18 \pm 0.27 \mathrm{~d}\end{array}$ \\
\hline
\end{tabular}

A Specific growth $=\frac{\begin{array}{l}\log , \text { of weight }- \text { log, of weight } \\ \text { at end }\end{array}}{\text { days fed }} \times 100$

B

Gross Feed Efficiency $=\frac{\text { total fish weight gain in grams }}{\text { total food (dry weight) offered in grams }} \times 100$

$\mathrm{C}$ Values are $\mathrm{x}+\mathrm{SE}, \mathrm{n}=2$. Values with different letter designations are significantly different $(p<0.05)$. 
Table 7. Specific growth rate and gross feed efficiency of spring chinook (Oncorhpnchus tshawytscha) fingerlings fed two diets containing different dietary concentrations of folic acid for 167 days. Immunological study. Abernathy Salmon Culture Technology Center, 1986.

\begin{tabular}{|c|c|c|c|}
\hline Diet & $\begin{array}{l}\text { Vitamin level } \\
\text { ng folic acid/kg dry diet }\end{array}$ & $\begin{array}{l}\text { Specific }{ }^{A, C} \\
\text { Growth Rate }\end{array}$ & $\begin{array}{c}\text { Gross }^{B, C} \\
\text { Feed Efficiency }\end{array}$ \\
\hline Abernathy & $\begin{array}{r}6 \\
10 \\
13 \\
17 \\
21\end{array}$ & $\begin{array}{l}1.61 \pm 0.02^{\mathrm{a}} \\
1.63 \pm 0.02^{\mathrm{a}} \\
1.61 \pm 0.01^{\mathrm{a}} \\
1.61 \pm 0.01^{\mathrm{a}} \\
1.60 \pm 0.01^{\mathrm{a}}\end{array}$ & $\begin{array}{l}85.15 \pm 1.77^{c} \\
87.22 \pm 3.28^{\prime} \\
85.73 \pm 1.17^{c} \\
85.29 \pm 0.80^{\prime} \\
84.62 \pm 0.69^{\prime}\end{array}$ \\
\hline Semi-purified & $\begin{array}{r}3 \\
7 \\
11 \\
14 \\
20\end{array}$ & $\begin{array}{l}1.52 \pm 0.00^{\mathrm{b}} \\
1.52 \pm 0.01 \mathrm{~b} \\
1.51 \pm 0.01 \mathrm{~b} \\
1.50 \pm 0.00^{\mathrm{b}} \\
1.50 \pm 0.00^{\mathrm{b}}\end{array}$ & $\begin{array}{l}73.44 \pm 0.39^{\mathrm{d}} \mathrm{d} \\
72.95 \pm 1.52^{\mathrm{d}} \\
71.63 \pm 0.01^{\mathrm{d}} \\
71.64 \pm 0.04^{\mathrm{d}} \\
72.00 \pm 1.53^{\mathrm{d}}\end{array}$ \\
\hline
\end{tabular}

A

\begin{tabular}{|c|c|c|}
\hline$t h=$ & $\begin{array}{c}\log _{\mathbf{e}} \text { of weight } \\
\text { at end }\end{array}$ & $\begin{array}{l}\text { of weight } \\
\text { at start }\end{array}$ \\
\hline
\end{tabular}

B

Gross Feed Efficiency $=\frac{\text { total fish weight gain in grams }}{\text { total food (dry weight) offered in grams }} \times 100$

$\mathrm{C}$ Values are $\mathrm{x}+\mathrm{SE}, \mathrm{n}=2$. Values with different letter designations are significantly different $(p<0.05)$. 
Table 8. Specific growth rate and gross feed efficiency of spring chinook (Oncorhynchus tshawytscha) fingerlings fed two diets containing different dietary concentrations of riboflavin for 90 days. Immunological study. Abernatay Salmon Culture Technology Center, 1986.

\begin{tabular}{lccc}
\hline \multicolumn{1}{c}{ Diet } & $\begin{array}{c}\text { Vitamin level } \\
\text { mg riboflavin/kg dry diet }\end{array}$ & $\begin{array}{c}\text { Specific } \\
\text { Growth Rate }\end{array}$ & $\begin{array}{c}\text { Gross } \\
\text { Feed }\end{array}$ \\
\hline Abernathy & 20 & 1.37 & 90.19 \\
& 65 & 1.39 & 92.30 \\
& 110 & 1.37 & 90.18 \\
& 155 & 1.40 & 92.70 \\
Semi-purified & 200 & 1.36 & 89.52 \\
& 5 & 1.35 & 90.27 \\
& 20 & 1.34 & 89.20 \\
& 65 & 1.34 & 89.11 \\
& 110 & 1.33 & 87.90 \\
& 155 & 1.31 & 87.26 \\
\hline
\end{tabular}

A

Specific growth $=\frac{\log _{\mathbf{e}} \text { of weight }-\log _{\text {, of weight }}}{\text { at end start }}$ days fed $\times 100$

B

Gross Feed Efficiency $=\frac{\text { total fish weight gain in grams }}{\text { total food (dry weight) offered in grams }} \times 100$

C All values were calculated from the means of fish weight and feed weight of the two replicate tanks of each vitamin level. 
Table 9. Specific growth rate and gross feed efficiency of spring chinook (Oncorhynchus tshawytscha) fingerlings fed two diets containing different dietary concentrations of pantothenic acid for 83 days. Immunological study. Abernathy Salmon Culture Technology Center, 1986.

\begin{tabular}{lccc}
\hline Diet & $\begin{array}{c}\text { Vitamin level } \\
\text { mg pantothenic acid/kg dry diet }\end{array}$ & $\begin{array}{c}\text { Specific } \\
\text { Growth Rate }\end{array}$ & $\begin{array}{c}\text { Gross,C } \\
\text { Feed Efficiency }\end{array}$ \\
\hline \multirow{2}{*}{ Abernathy } & 40 & 1.37 & 93.92 \\
& 130 & 1.40 & 94.82 \\
& 320 & 1.35 & 90.66 \\
& 40 & 1.44 & 98.85 \\
& 10 & 1.39 & 95.20 \\
Semi-purified & 10 & 1.45 & 102.99 \\
& 130 & 1.42 & 98.83 \\
& 220 & 1.42 & 99.65 \\
& 310 & 1.41 & 98.83 \\
& & 1.40 & 98.70 \\
\hline
\end{tabular}

A Specific growth $=\frac{\begin{array}{l}\text { loge of weight }- \text { loge of weight } \\ \text { at end }\end{array}}{\text { days fed }} \times 100$

B

Gross Feed Efficiency $=\frac{\text { total fish weight gain in grams }}{\text { total food (dry weight) offered in grams }} \times 100$

C All values were calculated from the means of fish weight and feed weight of the two replicate tanks of each vitamin level. 
than those fed the Abernathy diets. The same may also be said for feed conversion efficiency. There appears to be little definitive effect of pantothenic acid level on the growth and feed conversion efficiency produced by either diet. It should also be noted that the statistical analysis of the following data has not been completed, and will appear in the following annual and summary reports.

Effects of riboflavin on mitogenic responses to Vibrio anguillarum extract

In vitre test dates for both mitogenic stimulation and antibody formation included May 5, June 9, and July 14, 1987 for riboflavin in Abernathy and semi-purified diets, and May 19, June 23, and July 28, 1987 for the pantothenic acid groups. Due to culture problems, not all assays on July 14 and July 28 were able to be completed, thus these dates were deleted.

The data on the mitogenic responses of the salmonid lymphocytes to vibrio

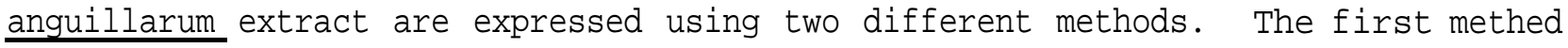
is the expression of the net counts per minute (net cpm), which is the total counts of tritiated thymidine incorporated into stimulated lymphocytes, minus the counts incorporated by unstimulated lymphocytes. The second method of expression is termed the stimulation index, which is the quotient derived by dividing the cpm of stimulated lymphocytes by the cpm of unstimulated lymphocytes. Background cpm were not depicted since they were routinely invariant between groups and demonstrated very low cpm (Fig. 14). Each method possesses its own value in the analyses of mitogenic responses, The value of net cpm is that it is more directly related to the absolute amount of proliferation occurring within the lymphocyte pool in response to a mitogen or antigen. Alternatively, the stimulation index takes into consideration the proliferative condition of the lymphocytes prior to exposure. For example, if 
a pool of lymphocytes has twice the background cpm as another pool (i.e. 400 VS. $200 \mathrm{cpm}$ ) the proliferative capacity of these ceils may be twice as great, therefore upon stimulation one may expect twice the cpm (i.e. 20000 vs. 10000). If only net cpm were evaluated, one would derive values of 19600 vs. 9800, whereas both groups would give stimulation indices of 10. Since both methods of expressing mitogenic data are used by various investigators, both methods were employed in this study to give a thorough analysis.

The first sampling of the riboflavin groups on May 5, 1987 revealed no differences in the net cpm (Fig. 1) or the stimulation indices (Fig.2) among the various vitamin concentrations incorporated into either diet. This sampling date is approximately three months after the fish were introduced to the test diet formulations. On June 9, a dramatic difference arose between all diets of the Aber nathy formulation and those of the semi-purified diet formulation. All Abernathy test groups gave distinctly higher net cpm (Fig. 3) values and stimulation indices (Fig. 4), than did the semi-purified diet groups. There appeared to be no difference among vitamin groups within either diet, with the possible exception of the $155 \mathrm{mg} / \mathrm{Kg}$ concentration in the Xbnernathp diet (Fig. 3). It appears that an upward trend was occurring. However, it must be noted that the lowest value of $20 \mathrm{mg} / \mathrm{Kg}$ gave almost the same value as did one replicate of the $200 \mathrm{mg} / \mathrm{Kg}$ diet.

Effect of pantothenic acid concentrations on mitogenic responses to Vibrio anguillarum extract

No differences in mitogenic responses were observed among the 


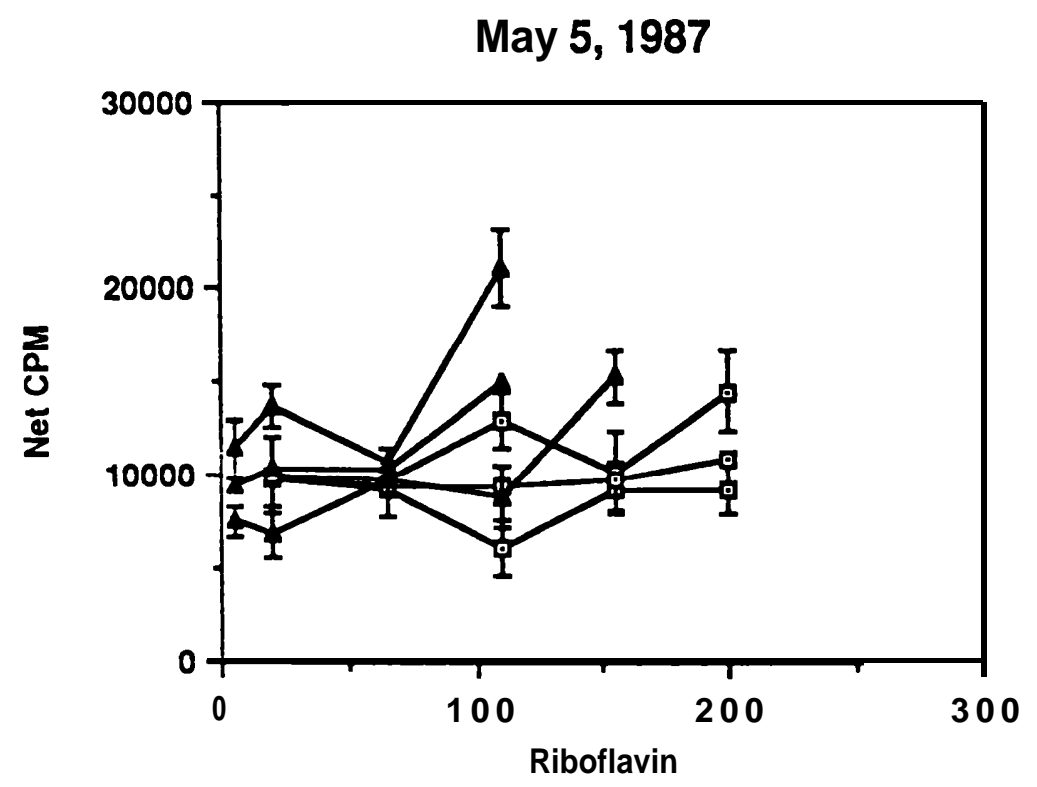

Figure 1. Effect of riboflavin on the mitogenic response to Vibrio anguillarum (net cpm) on the first test date Each fish (anterior kidney) was sampled twice and the average value used in the determination of mean value for the $24 \mathrm{fish}$ in one replicate. Each point, which possesses error bars, represents the mean of 24 fish from one replicate. Error bars represent two standard errors about each mean. The point without error bars represents the mean of the two replicates. Depicted are the replicates and resultant mean for the Abernathy diets ( $=$ ) and the semi-purified diets (A). 


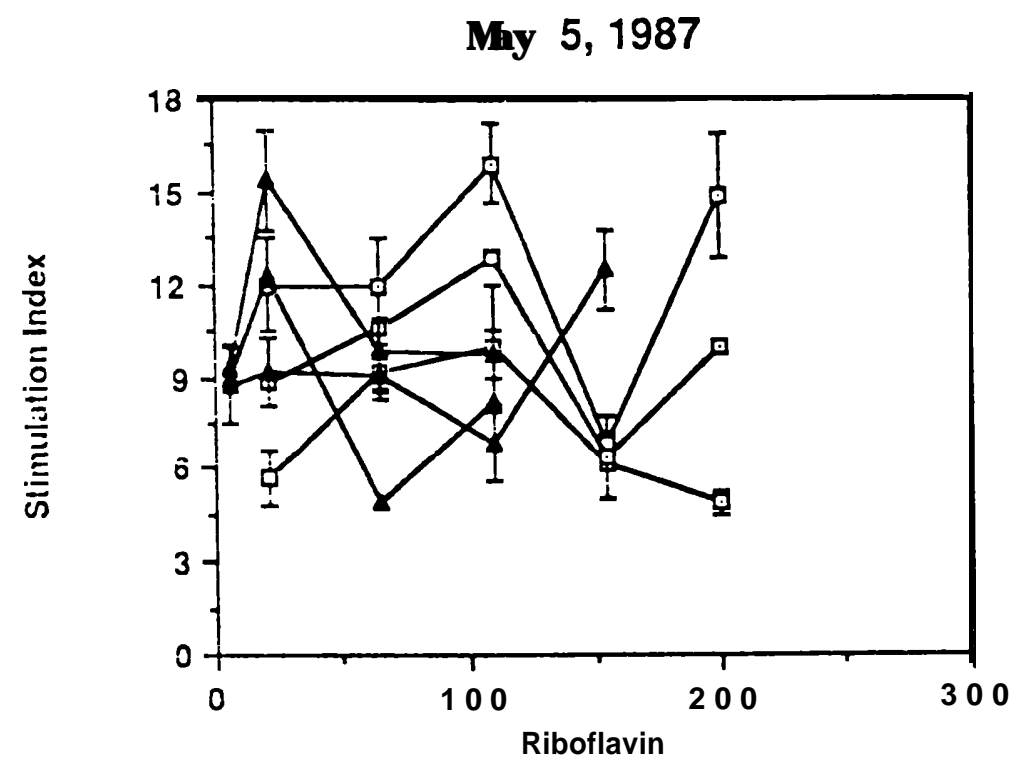

Figure -. Effect of riboflavin on the nitogenic response to Vibrio anguillarum (stimulation index) on the first test date Each fish (anterior kidney) was sampled twice and the average value used in the determination of mean value for the 24 fish in one replicate. Each point, which possesses error bars, represents the mean of 24 fish from one replicate. Error bars represent two standard errors about each mean. The point wi thout error bars represents the mean of the two replicates. Depic ted arethe replicates and resultant mean for the Abernathy $\operatorname{diets}(\because-)$ and the semi-purified diets ( A). 


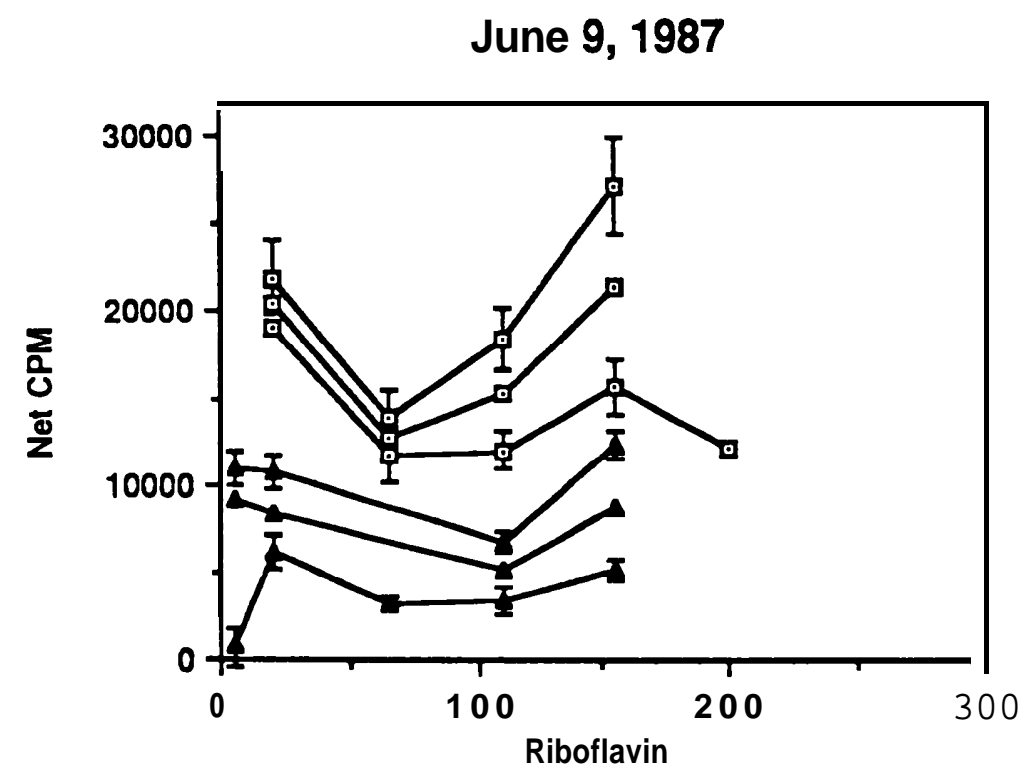

Figure 3. Effect of riboflavin on the mitogenic response to Vibrio anguillarum (net cpm) on the second test date Each fish (anterior kidney) was sampled three times and the average value used in the determination of mean value for the $24 \mathrm{fish}$ in one replicate. Each point, which possesses error bars, represents the mean of 24 fish from one replicate. Error bars represent two standard errors about each mean. The point without error bars represents the mean of the two replicates. Depicted are the replicates and resultant mean for the Abernathy diets ( $匚$ ) and the semi-purified diets (A). 


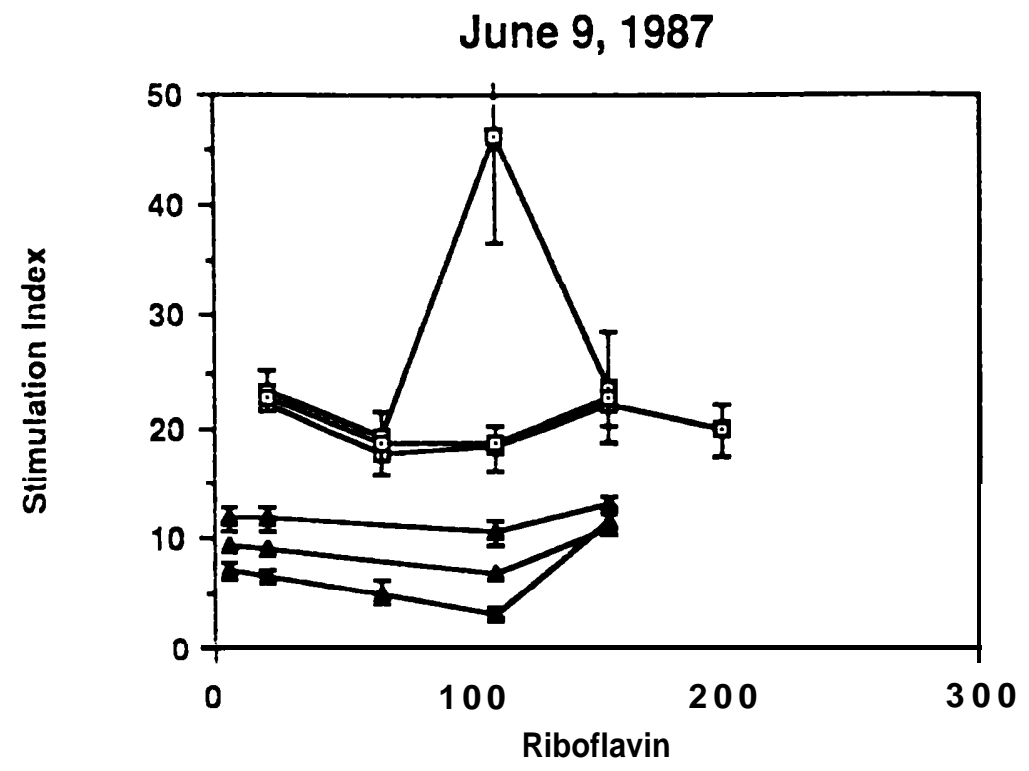

Figure 4. Effect of riboflavin on the mitogenic response to Vibrio anguillarum (stimulation index) on the second test date Each fish (anterior kidney) was sampled three times and the average value used-in the determination of mean value for the $24 \mathrm{fish}$ in one replicate. Each point, which possesses error bars, represents the mean of 24 fish from one replicate. Error bars represent two standard errors about each mean. The point without error bars represents the mean of the two replicates. Dipicted are the replicates and resultant mean for the Abernathy diets $(=)$ and the semi-purified $\operatorname{diets}(\boldsymbol{\Lambda})$. 
vitamin concentrations in either diet formulation on the first test date, May 19, 1987 (Fig. 5 and 5) or the second test date, June 221987 (Fig. 7 and 8). Once again, however the magnitude of the responses for all Abernathy diets was substantially higher than the responses found with the semi-purified diets.

Effect of riboflavin concentrations on antibody production

In vitre plaque forming cell responses to trinitrophenylated lipopolysaccharide (TNP-:PS) appeared to be unaffected by differences in riboflavin concentrations when administered in either Abernathy or semi purified diets (Fig. 9). The dates for PFC analysis of June 9 and July 14 were not included, since technical errors were responsible for a large number of cultures with no responses, therefore it was considered inappropriate to include these dates in the present analysis.

Effect of pantothenic acid concentrations on antibody production

The first assay of May 19, 1987, demonstrated no distinct trend as to an optimal concentration of pantothenic acid for either diet, although higher PFC responses were observed at $130 \mathrm{mg} / \mathrm{Kg}$ in the Abernathy diet while peak responses were observed at $220 \mathrm{mg} / \mathrm{Kg}$ within the semi-purified diet (Fig. 10) Subsequent testing of the groups one month later revealed the same pattern no longer existed (Fig. 11). There were no distinguishable differences between the various vitamin concentrations in the semi-purified diets, whereas the Abernathy diet revealed a trend that gave the highest response at $400 \mathrm{mg} / \mathrm{Kg}$. 


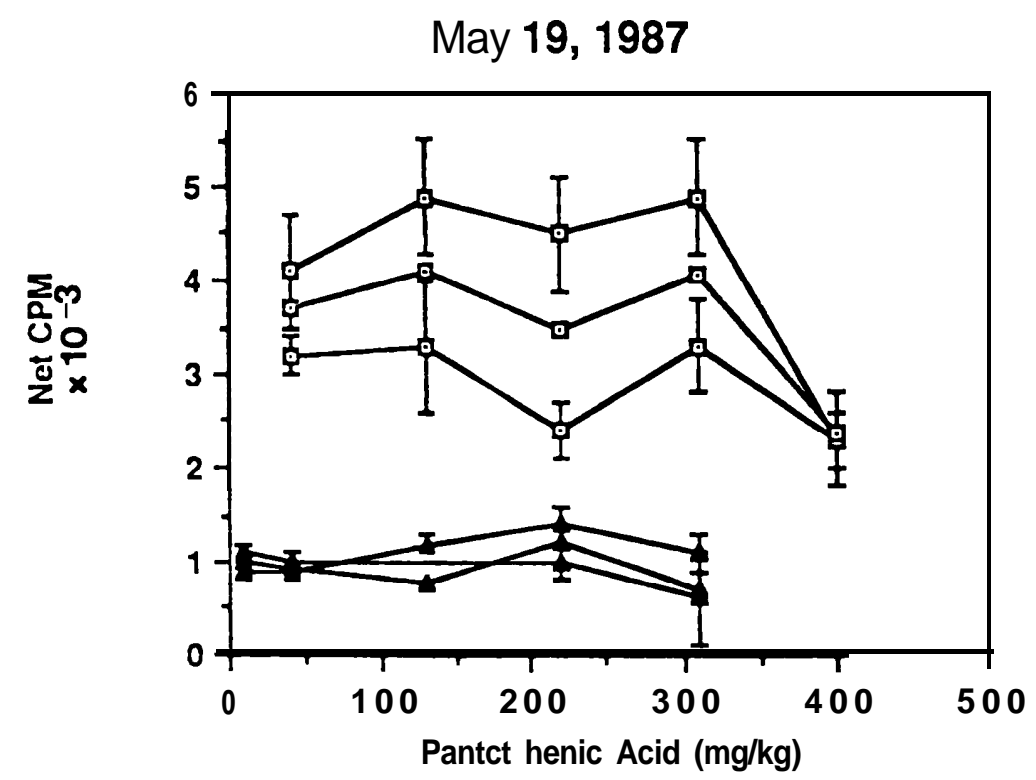

Figure 5. Effect of pantothenic acid on the mitogenic response to Vibrio (anterior kidney) was sampled three times and the average value used in the determination of mean value for the 24 fish in one replicate. Each point, which possesses error bars, represents the mean of 24 fish from one replicate. Error bars represent two standard errors about each mean. The point without error bars represents the mean of the two replicates. Depicted are the replicates and resultant mean for the Abernathy diets ( ( ) and the semi-purified diets (A). 


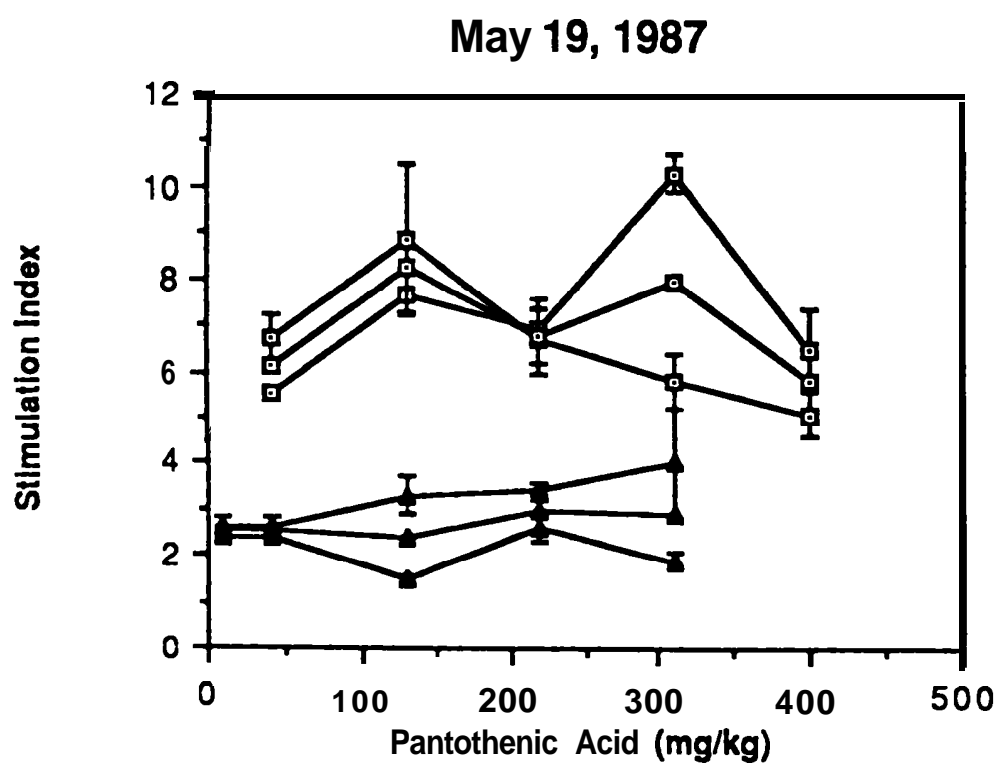

Figure 6. Effect of pantothenic acid on the mitogenic response to Vibrio anguillarum (stimulation index) on the first test date Each fish (anterior kidney) was sampled three times and the average value used in the determination of mean value for the $24 \mathrm{fish}$ in one replicate. Each point, which possesses error bars, represents the mean of 24 fish from one replicate. Error bars represent two standard errors about each mean. The point without error bars represents the mean of the two replicates. Depicted are the replicates and resultant mean for the Abernathy diets ( $\square$ ) and the semi-purified diets (A). 


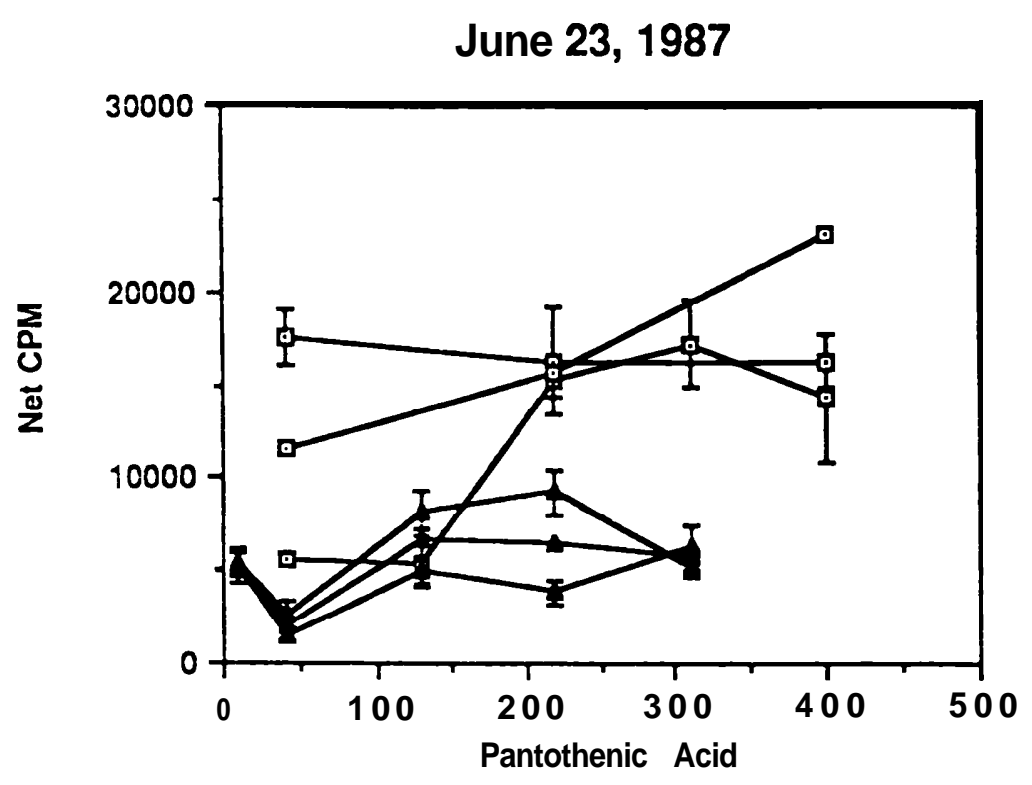

Figure 7. Effect of pantothenic acid on the mitogenic response to Vibrio anguillarum (net cpm) on the second test date Each fish (anterior kidney) was sampled three times and the average value used in the determination of mean value for the 24 fish in one replicate. Each point, which possesses error bars, represents the mean of $24 \mathrm{fish}$ from one replicate. Error bars represent two standard errors about each mean. The point without error bars represents the mean of the two replicates. Depicted are the replicates and resultant mean for the Abernathy diets $(=)$ and the semi-purified diets (A). 


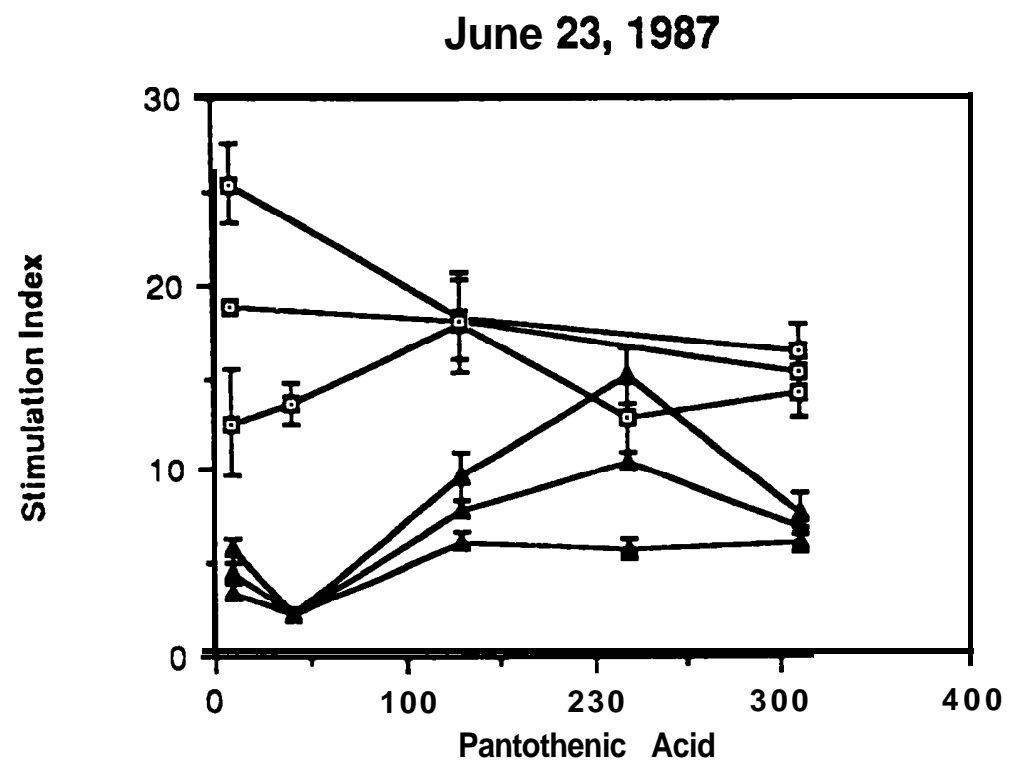

Figure 8. Effect of pantothenic acid on the mitogenic response to Vibrio anguillarum (stimulation index) on the second test date Each fish (anterior kidney) was sampled three times and the average value used in the determination of mean value for the $24 \mathrm{fish}$ in one replicate. Each point, which possesses error bars, represents the mean of 24 fish from one replicate. Error bars represent two standard errors about each mean. The point without error bars represents the mean of the two replicates. Depicted are the replicates and resultant mean for the Abernathy diets (0) and the semi-purified diets (A). 


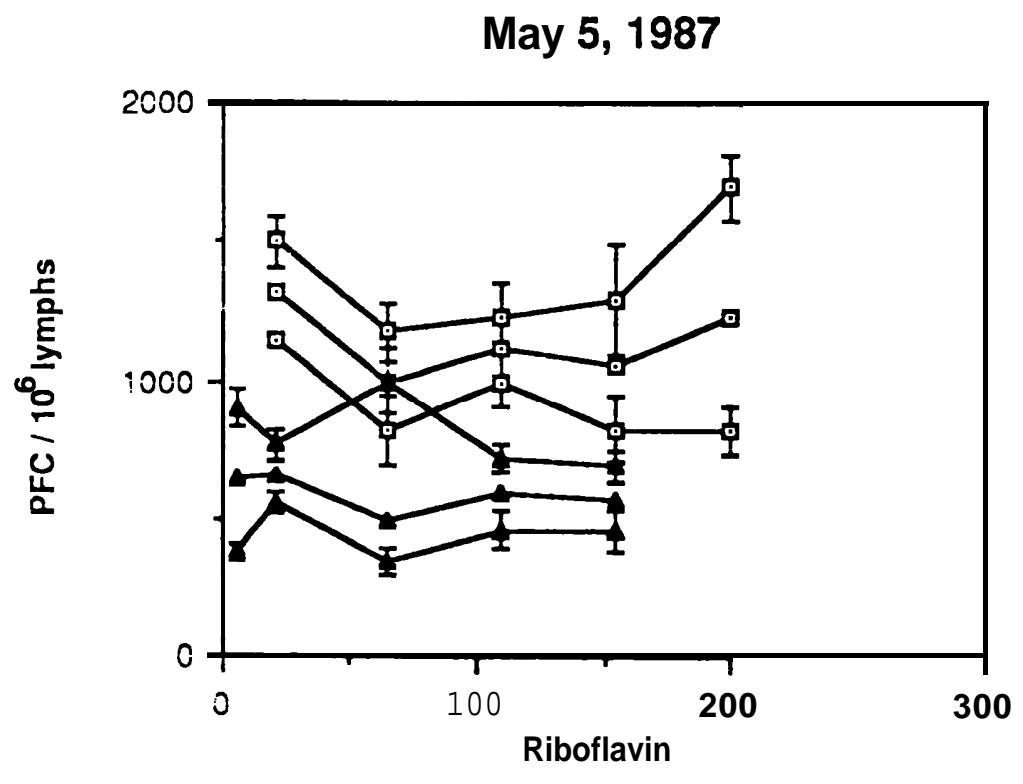

Figure 9. Effect of riboflavin on the plaque-forming cell response to TNP-LPS on the first test date Each fish (anterior kidney) was sampled three times and the average value used in the determination of mean value for the $24 \mathrm{fish}$ in one replicate. Each point, which possesses error bars, represents the mean of 24 fish from one replicate. Error bars represent two standard errors about each mean, The point without error bars represents the mean of the two replicates. Depicted are the replicates and resultant mean for the Abernathy diets ( $C$ ) and the seni-purified diets (A). 


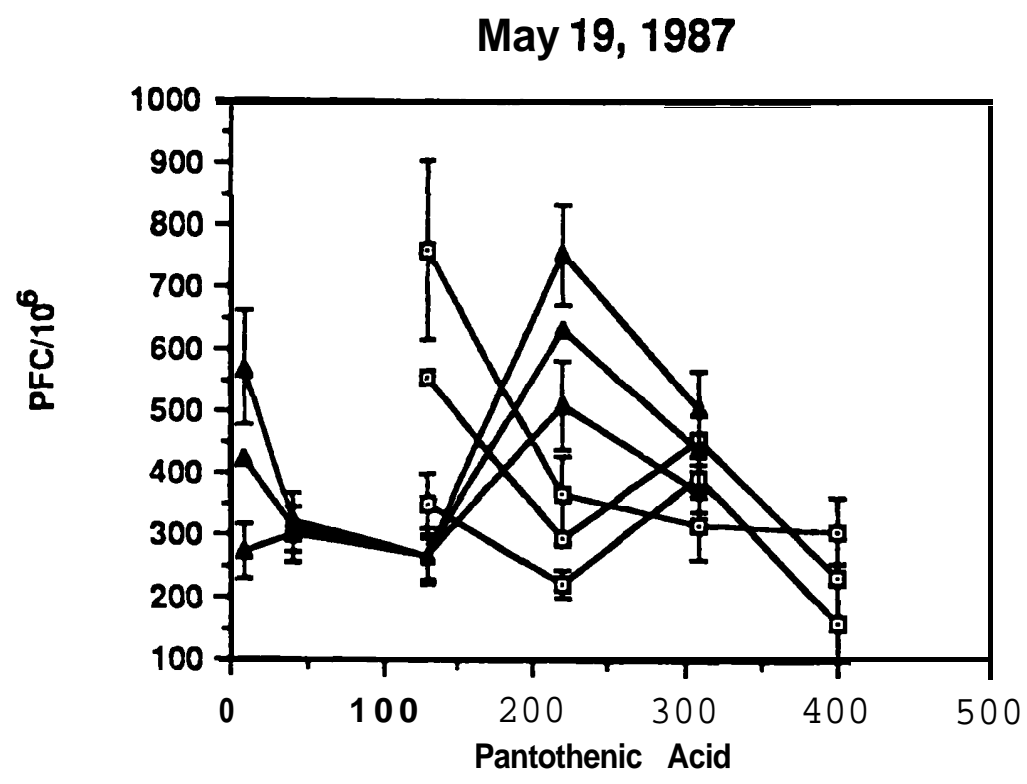

Figure 10. Effect of pantothenic acid on the plaque-forming cell response to TKP-LPS on the first test date Each fish (anterior kidney) was sampled three times and the average value used in the determination of mean value for the 24 fish in one replicate. Each point, which possesses error bars, represents the mean of 24 fish from one replicate. Error bars represent two standard errors about each mean. The point without error bars represents the mean of the two replicates. Depicted are the replicates and resultant mean for the Abernathy diets $(\square)$ and the semi-purified diets $(\boldsymbol{\Delta})$. 


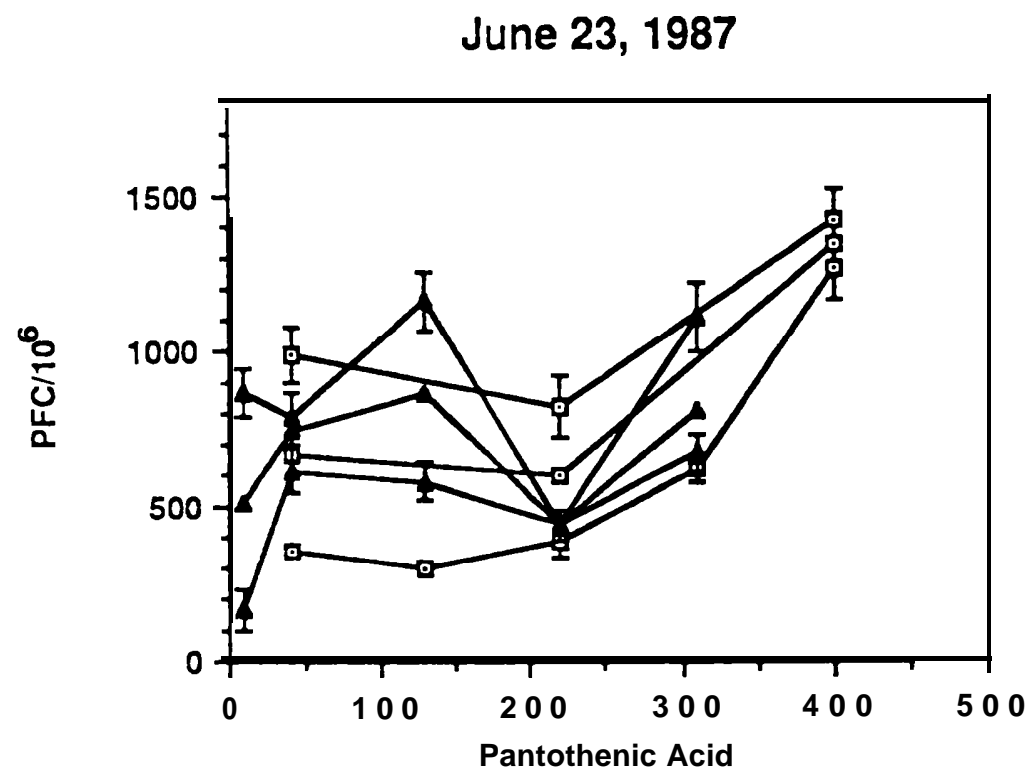

figure 11 Effect of pantothenic acid on the plaque-forming cell response to TN P-LPS on the second test date Each fish (anterior kidney) wa s sampled three times and the average value used in the -determination of mean value for the $24 \mathrm{fish}$ in one replicate. Each point, which possesses error bars, represents the mean of 24 fish from one replicate. Error bars represent two standard errors about each mean. The point without error bars represents the mean of the two replicates. Depicted are the replicates and resultant mean for the Abernathy diets ( $\Sigma$ ) and the semi-purified diets (A). 
Since no statistical differences were observed among any vitamin concentrations in either diet, the means of the mitogenic responses for all groups of the Abernathy and the Semi-purified formulations were averaged and their respective means and standard errors were calculated and plotted. The net cpm values were distinctly higher for the Abernathy diets than the Semi-purified diets on May 19, June 9, and June 23 (Fig. 12). This increased responsiveness of fish held on the Abernathy diet was also seen with respect to the stimulation index (Fig. 13). No such differences between the two diets were observed with respect to background stimulation (Fig.14). This would indicate that the effect on Vibrio anquillarum responsiveness is not a general phenomenon, but rather a direct effect on polyclonal activation or specific antigen stimulation of the lymphocytes by Vibrio antigens or mitogens The effect of age on the ability of fish to produce antibody-producing cells also demonstrated an enhancement of this form of immunity with fish held on the Abernathy diet (Fig. 15). It is of particular interest to note the general decrease in immune responsivenes to the TNP-LPS over time. Such a decrease did not occur with the responses to Vibrio anquillarum extract (Fig. 12 and 13).

Effect of age and diet group on immune responsiveness

Upon the examination of the effect of age on the immune response a direct relationship seemed skeved due to the dramatic drop in responsiveness on May 19 (Fig. 12 and 13) and the minor drop on June 23. 


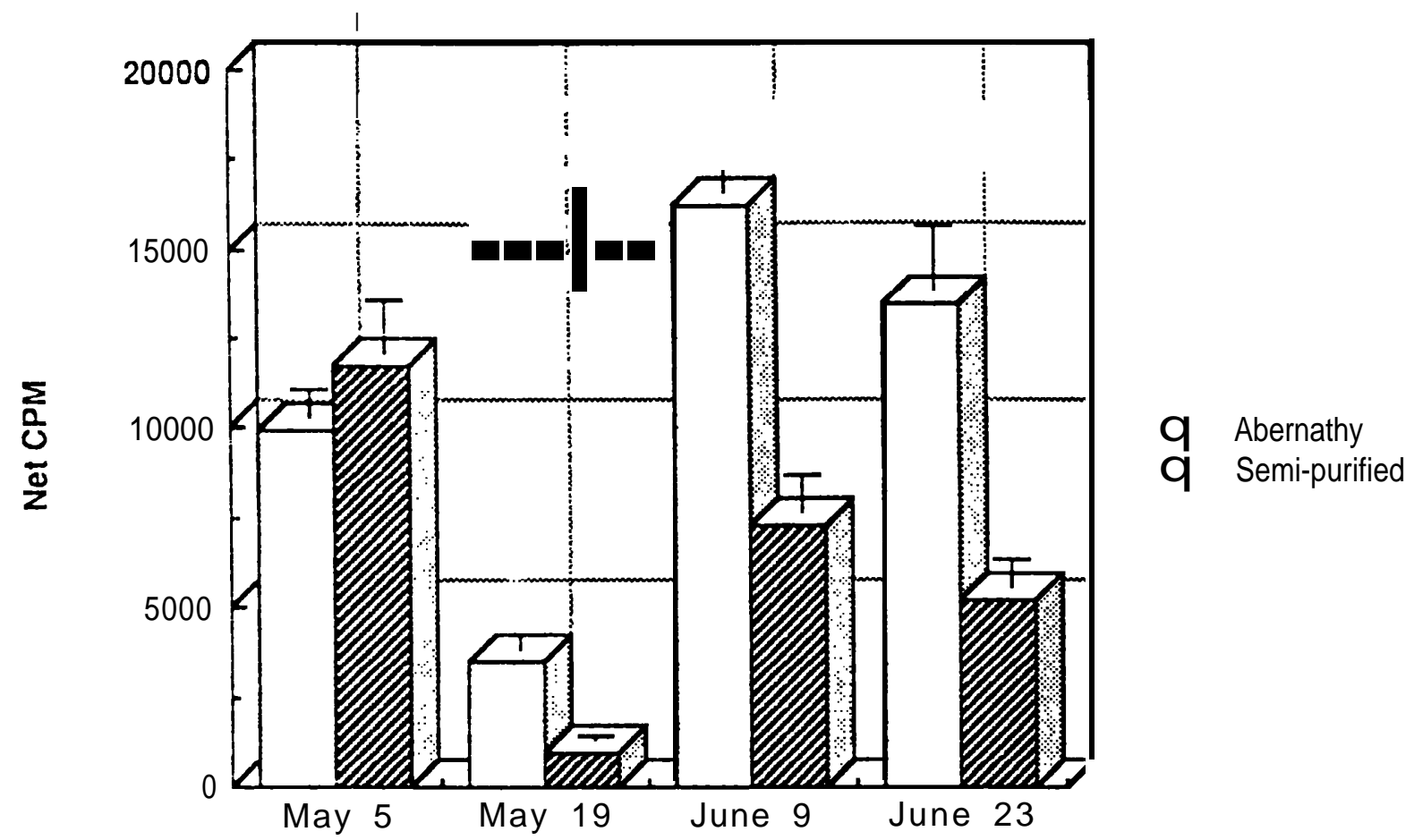

Figure 12. Effect of age on the mitogenic response (net cpm). Abernathy. groups( 10) and the riboflavin/semi-purified groups (10) are depicted as $\mathrm{t} h$ e columns. Each error $\therefore$ al. : e resent: one standsrd crros ahove t'ne aean. 


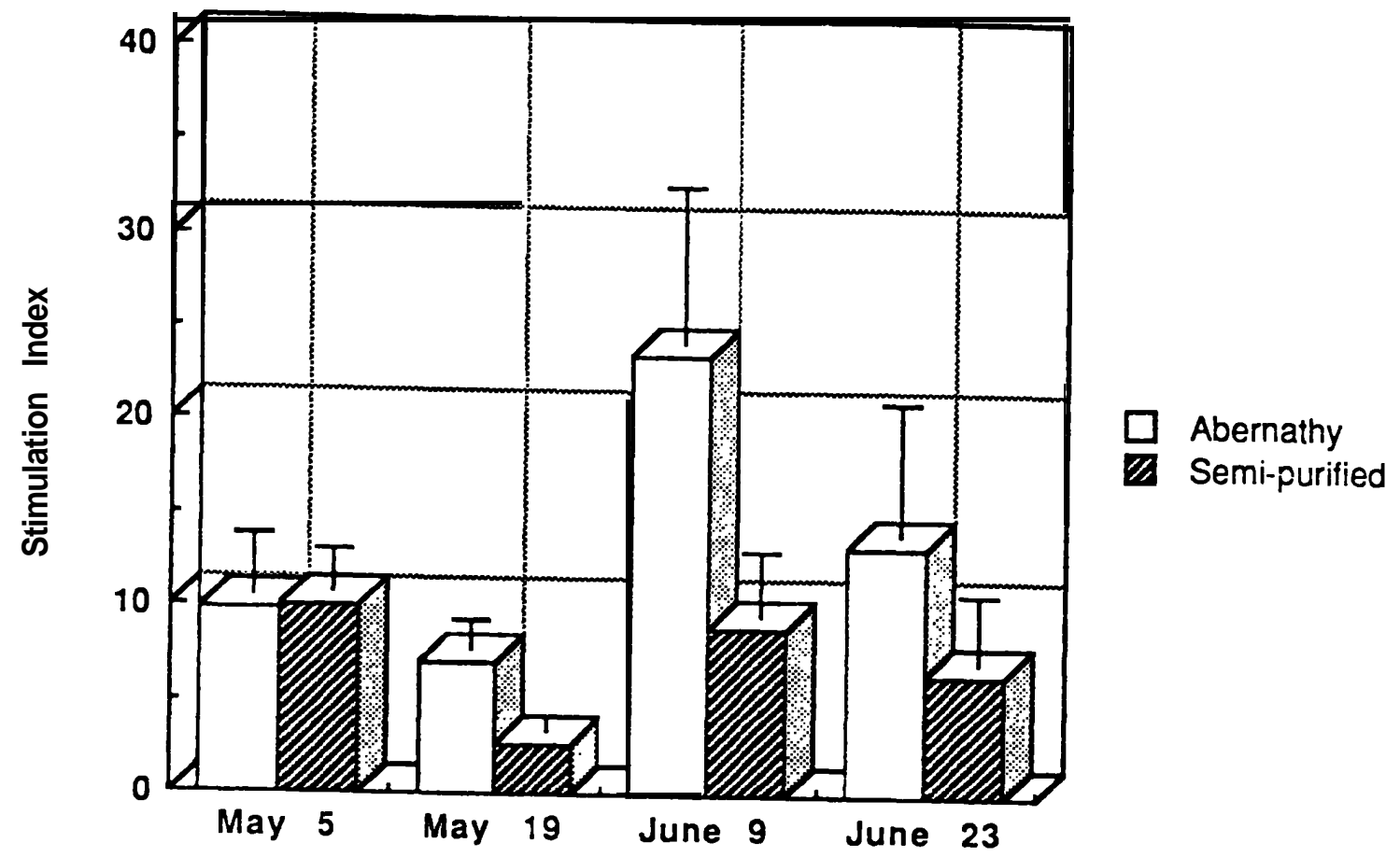

Figure 13. Effect of age on the mitogenic response (stimulation index). The mean values of the stimulation index for the riboflavin/ Abernathy groups(10) and the riboflavin/semi-purified groups (10) are depicted as the columns. Each error bar represents one standard error above the mean. 


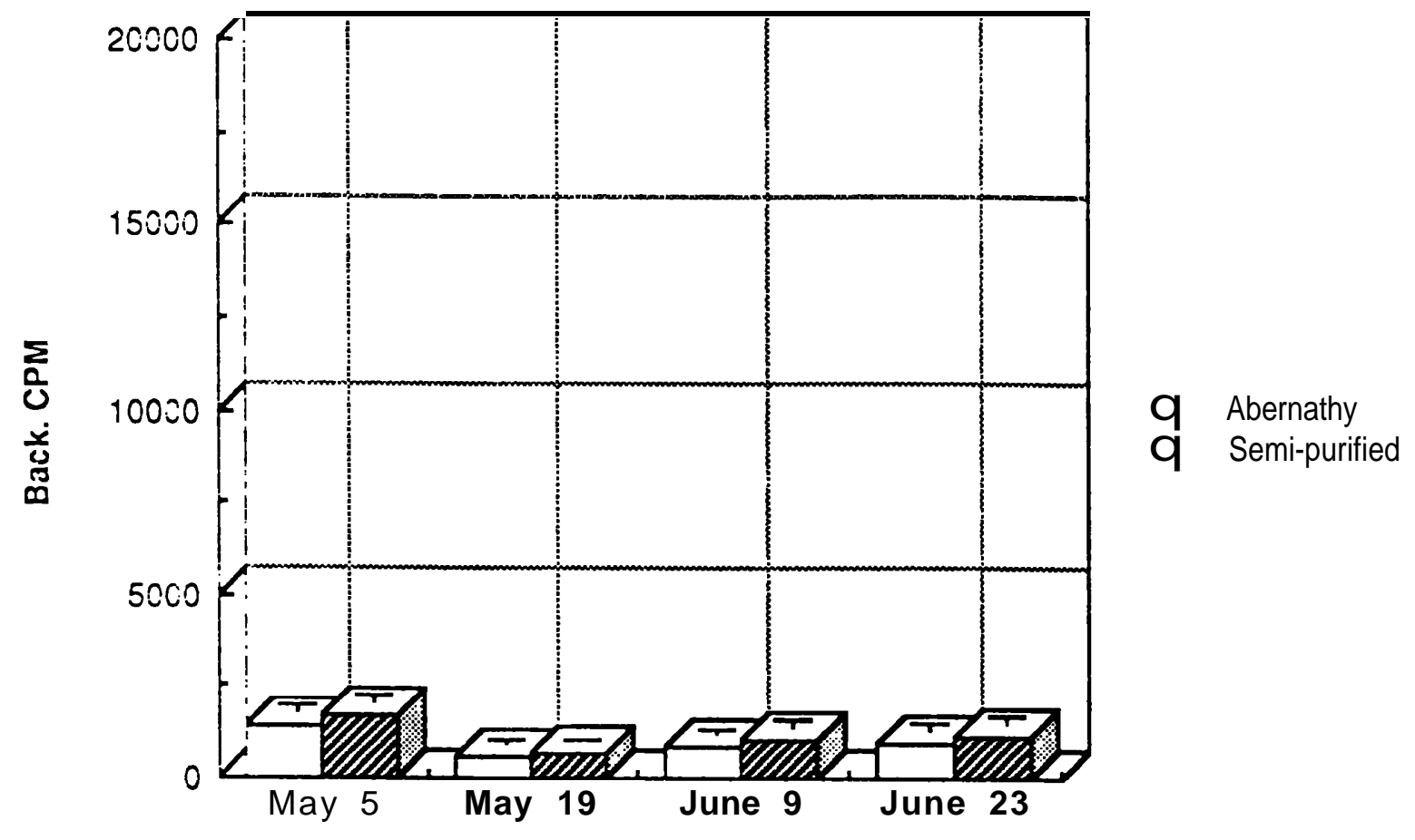

Figure 14. Effect of age on the mitogenic response (background cpm). Abernathy groups(10) and the riboflavin/semi-purified groups (1) are depicted as the columns. Each error bar represents one standard error above the mean. 


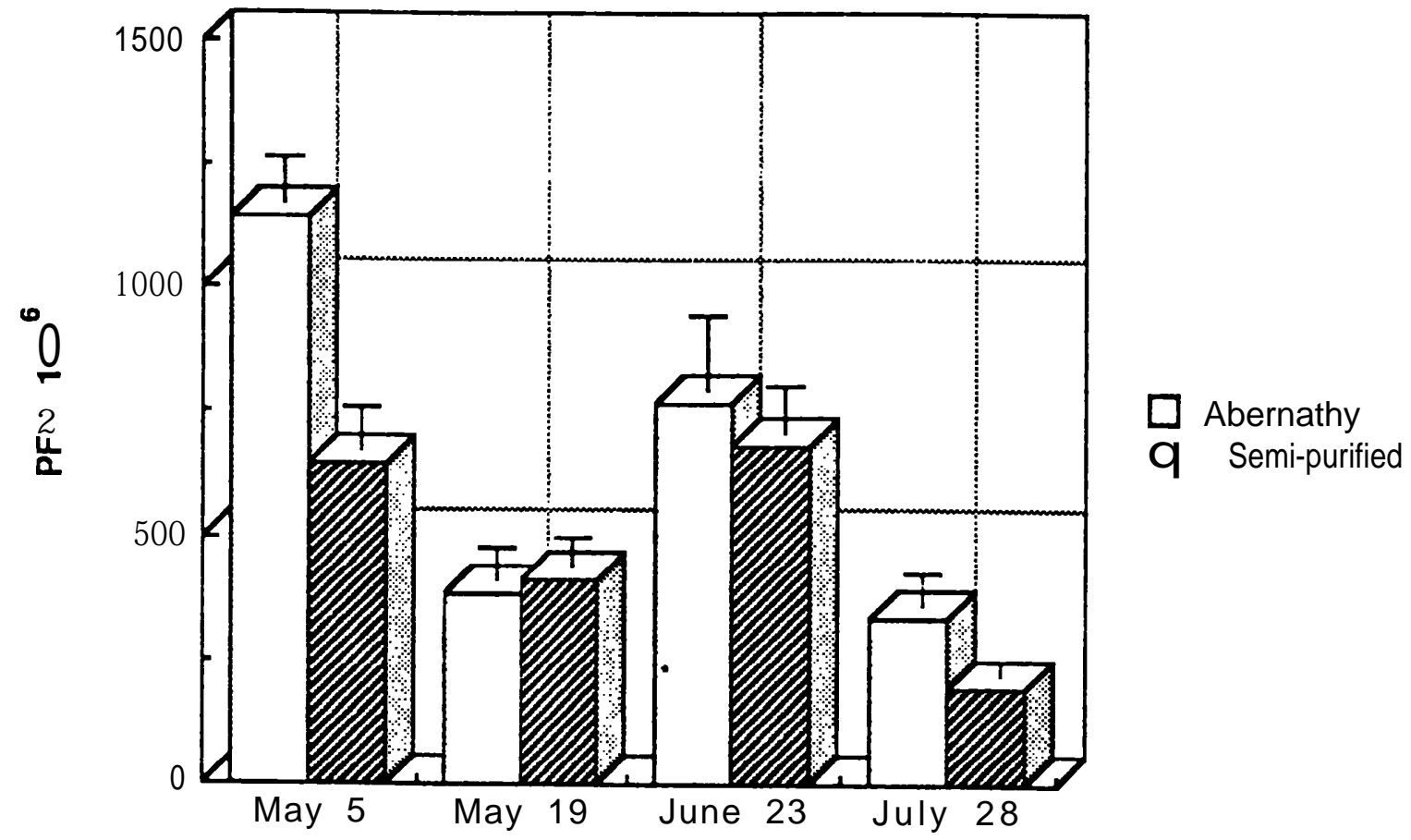

Figure 15. Effect of age on the antibody response (PFC). Abernathy groups $(W)$ and the riboflavin/semi-purified groups (10) are depicted as the columns. Each error bar represents one standard error above the mean. 
distinct experimental groups (pantothenic acid groups). The data was therefore also compared by separting the gropus on the basis on the vitamin studied. As can be seen from figures 16 and 17, there does appear to be a more direct relationship between age and the development of immune responsiveness to Vibrio anguillarum extract when these groups are examined separately. Also, when the PFC information is plotted in this manner the downward trend of the antibody response to TNP becomes more readily apparent (Fig. 18).

It is not clear at this time why the riboflavin and pantothenic acid groups should exhibit such differences in responsivenss. All riboflavin diets have more than the standard National Research Council (NRC) requirement for pantothenic acid and all pantothenic groups have more than the standard NRC requirement for riboflavin, thus these differences cannot be related to the vitamins within the diets. It is possible that these differences occur due to The fact that all riboflavin groups are tested on different days than the pantothenic acid groups (two weeks difference), or alternatively, the base Compostion of the diets may be different in some component(s) of which we are not aware. The latter alternative is unlikely since all of the base components were prepared from the same stock ingredients.

Effect of age and diet group on the increase in immune responsiveness within each replicate tank

The mean net cpm for each replicate of 24 fish was calculated and the Per cent increased in responsiveness over time was calculated for each replicate (Table 10). There was no increase in the per cent increase in the net cpm to Vibrio anguillarum for the riboflavin groups fed the 


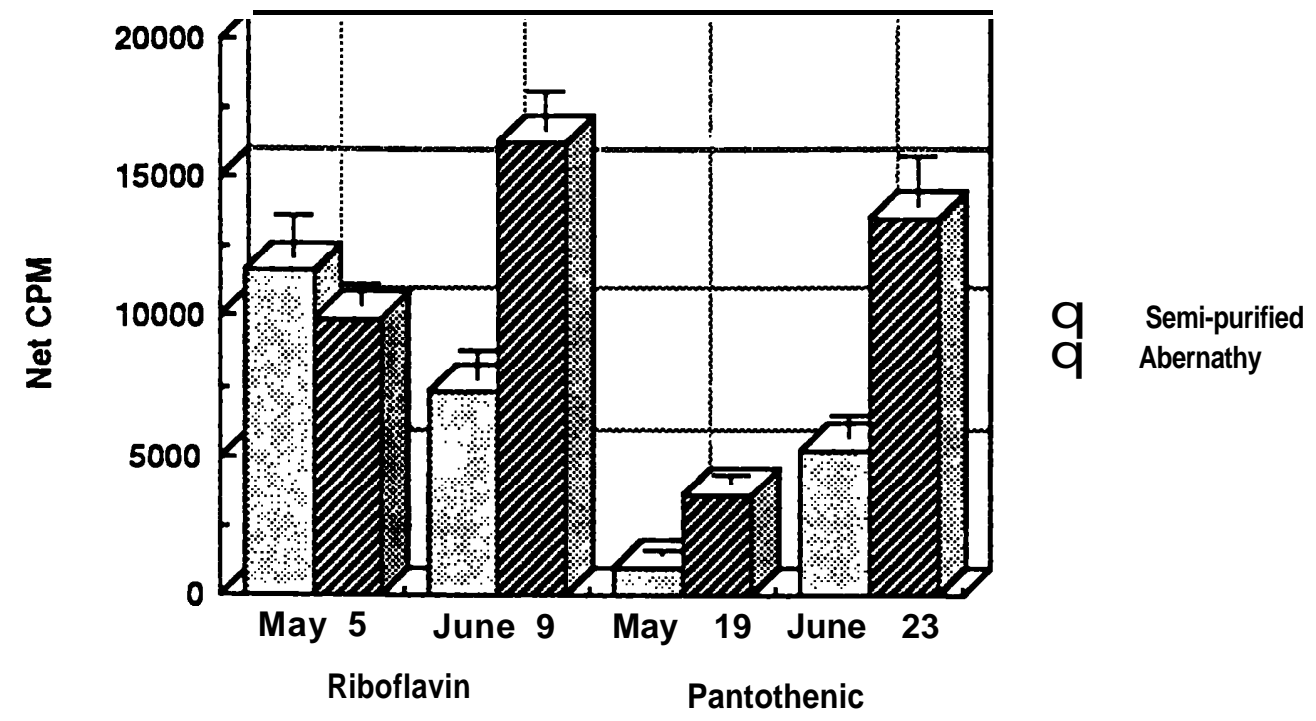

Figure 16. Effect of age and vitamin group on the mitogenic response (net cpm). The mean values of the net cpm for the riboflavin/Abernathy groups(10) and the riboflavin/semi-purified groups (10) are depicted as the columns. Each error bar represents one standard error above the mean. 


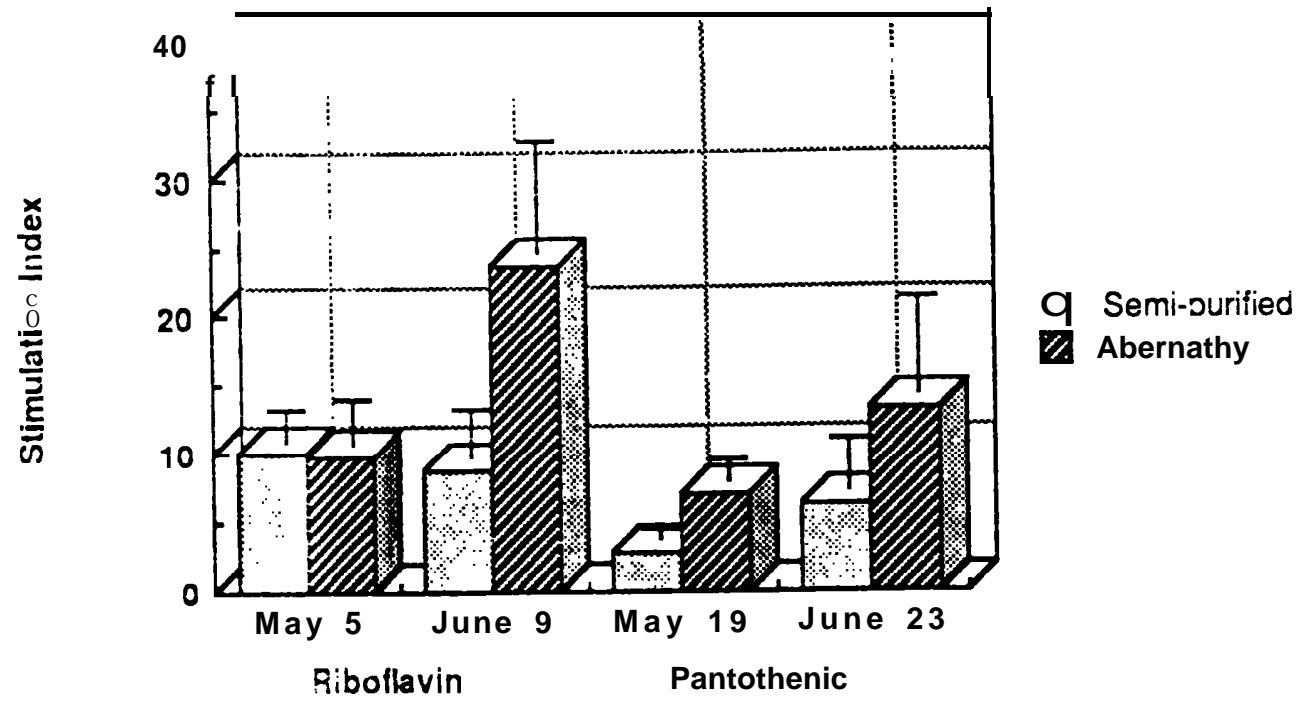

Figure 17. Effect of age andvitamin group on the mitogenic response (stimulation index). The mean values of the stimulation index for the riboflavin/Abernathy groups(10) and the riboflavin/semipruified grops ( 10) are depicted as the columns. Each error bar represents one standard error above the mean. 


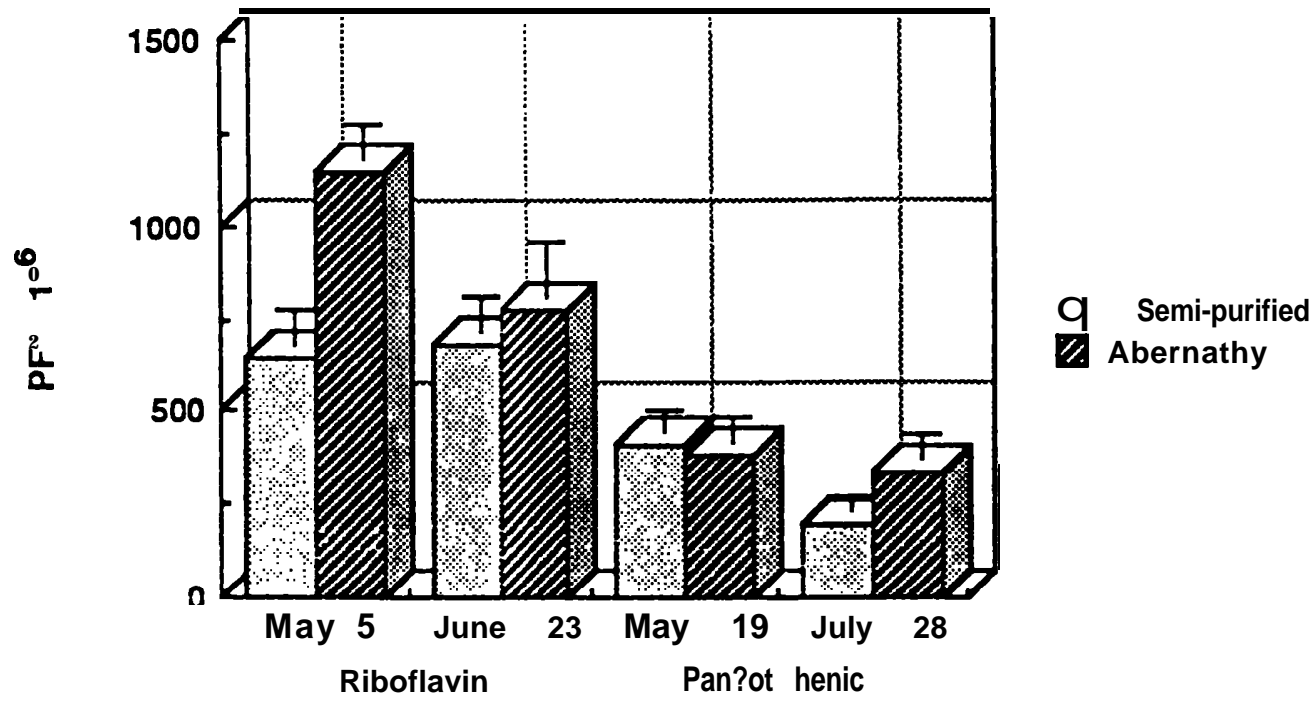

Figure 18. Effect of age and vitamin group on the antibody response (PFC). The mean values of the $\mathrm{PFC}$ for the riboflavin/Abernathy groups (10) and the riboflavin/semi-purified groups (10) are depicted as the columns. Each error bar represents one standard error above the mean. 
Table 10. Effect of age on the mitogenic response (net cpm) of the riboflavin diet groups. Values represent the mean net cpm derived from the sampling of 24 fish from each tank. ㅇf represents the per cent increase in the net cpm between May 5 and June 6, 1987 for each replicate. The mean increase and standard error of the mean for the pool of the semipurified and Abernathy diet groups is shown.

Semi-purified Diet

\begin{tabular}{|c|c|c|c|c|c|c|c|}
\hline Tank & $5 / 5 i \times i$ & $6 / 9 / 87$ & $\div$ Diff & Tank & $5 / 5 / 87$ & $6 / 9 / 87$ & $\div$ Diff \\
\hline 12 & 11396 & 10894 & -4.4 & $6 \mathrm{~A}$ & 9821 & 21843 & 123.4 \\
\hline $1 B$ & 0007 & 10727 & 56.0 & $6 \mathrm{~B}$ & 9767 & 13834 & 41.6 \\
\hline $2 \mathrm{~A}$ & $9 \times 2$ & 3204 & $-6 i . s$ & $7 \mathrm{~A}$ & 12897 & 18491 & 43.4 \\
\hline $2 \mathrm{~B}$ & $x y 201$ & 6763 & -24.2 & $7 \mathrm{~B}$ & 10223 & 21254 & 107.9 \\
\hline $3 A$ & $152 \times i$ & 12316 & -19.4 & $8 \mathrm{~A}$ & 14496 & 12154 & 107.9 \\
\hline $3 B$ & 7576 & 7379 & -2.4 & $8 B$ & 10022 & 19069 & 90.3 \\
\hline $4 A$ & 13714 & 6132 & -55.3 & $9 \mathrm{~A}$ & 9196 & 11687 & 27.1 \\
\hline $4 \mathrm{E}$ & 1075 & $\mathrm{NA}$ & $\mathrm{NA}$ & $9 B$ & 6157 & 11991 & 94.7 \\
\hline $5 A$ & 21136 & 3479 & -83.5 & $10 \mathrm{~A}$ & 9327 & 15745 & 68.9 \\
\hline \multirow[t]{2}{*}{$5 \mathrm{hi}$} & $\because A$ & $5193 \mathrm{NA}$ & & $10 \mathrm{~B}$ & 7320 & $\mathrm{NA}$ & NA \\
\hline & & Mean $=-$ & $6 \pm 15$ & & & Mean $=$ & $64 \pm 15$ \\
\hline
\end{tabular}

Abernathy Diet 
in the net cpm to Vibrio anguillarum for the riboflavin groups fed the semi-purified diet between May 5 and June $6(-16 \%+15 \%)$, however the fish fed the same vitamin concentrations in Abernathy diet demonstrated a mean increase of $64 \%+15 \%$ over the same time period. This same increase in sensitivity to Vibrio was also reflected in the stimulation indices (Table 11) for each replicate (semi-purified $=-12.3 \%+14 \%$ vs. Abernathy $=150 \%+32 \%$ ).

Examination of the pantothenic acid groups with respect to the individual percent increases with each replicate group revealed a different pattern (Table 12 and 13). With respect both to net cpm (Table 12) and stimulation indices (Table 13) the per cent increase in responsiveness is for both semi-purified and Abernathy diets. It, however, is obvious that the net cpm values and the stimulation indices are approximately four-fold lower in the semi-purified groups than in the Abernathy groups. Re-examination of the riboflavin groups (Table 10 and 11) reveal that although there is no net increase in the responses between the two dates, the net cpm and stimulation indices are approximately equiva lent on the first test date. This data would indicate that the immune responsiveness of the semi-purified riboflavin diet groups had developed in manner comparable to that of the Abernathy groups until May 5, but from that time point the development of responsiveness was arrested In contrast, the semi-purified panthothenic acid groups were continuing to develop their responsiveness to Vibrio, but the absolute magnitude of the responses were at least one third the magnitude of the Abernathy groups.

In mammalian species (Sherwin and Roelants, 1974: Teale, 1985), variations in the acquisition of certain antigenic specificities appears to occur during development. The relative proportions of lymphocytes committed to a particular specificity do develop in different temporal orders. This may 
Table 11. Effect of age on the mitogenic response (stimulation index) of the riboflavin diet groups. Values represent the mean stinualtion index derived from the sampling of 24 fish from each tank. $\div$ Diff represents the per cent increase in the stimulation index between May 5 and June 6, 1987 for each replicate. The mean increase and standard error of the mean for the pool of the semi-purified and Abernathy diet groups is shown.

Semi-purified Diet

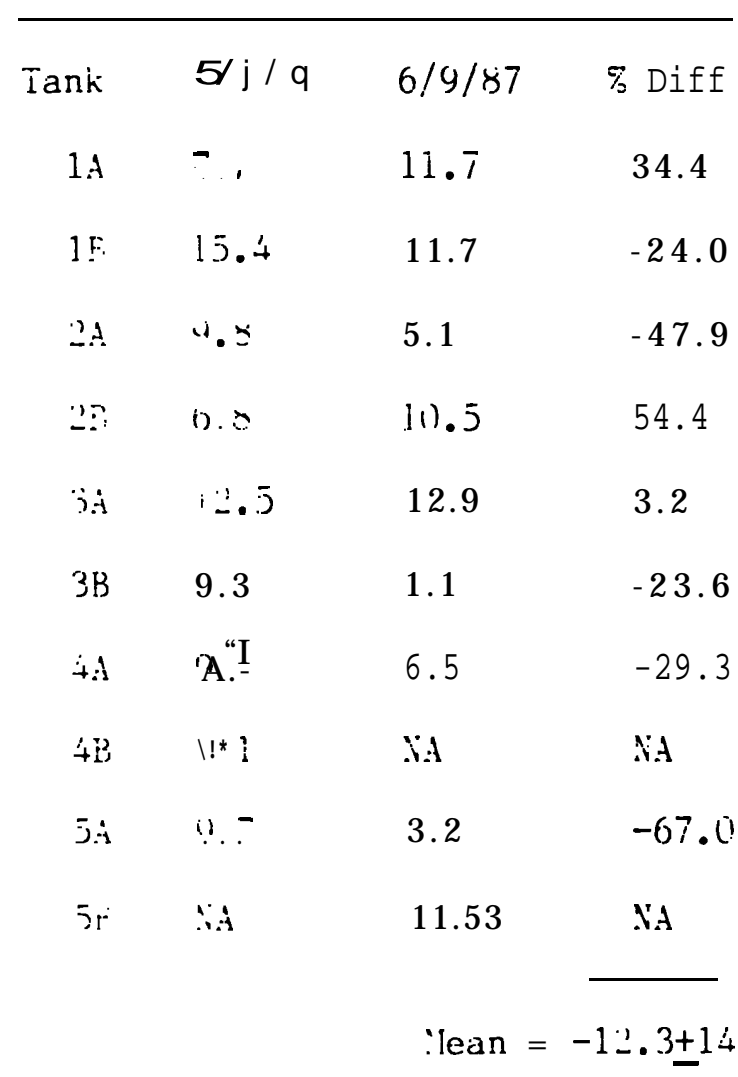

Abernathy Diet

\begin{tabular}{|c|c|c|c|}
\hline Tank & $5 / 5 / 87$ & $6 / 9 / 87$ & $\not D$ Diff \\
\hline $6 A$ & 12.0 & 23.3 & 93.5 \\
\hline $6 \mathrm{~B}$ & 9.2 & 17.8 & 93.5 \\
\hline $7 \mathrm{x}$ & 15.97 & 46.21 & 190.6 \\
\hline $7 \mathrm{~B}$ & 6.1 & 23.b & 286.9 \\
\hline $8 \mathrm{~A}$ & 14.9 & 19.8 & 32.9 \\
\hline $8 \mathrm{~B}$ & 5.7 & 22.0 & 286.0 \\
\hline $9 \mathrm{~A}$ & 12.0 & 19.2 & 60.0 \\
\hline $9 \mathrm{~B}$ & 9.9 & 18.2 & 83.8 \\
\hline $10 \mathrm{~A}$ & 6.8 & 22.1 & 225.0 \\
\hline $10 \mathrm{~B}$ & 4.920 & $\therefore A$ & $\mathrm{NA}$ \\
\hline & & :lean & $50 \pm 32$ \\
\hline
\end{tabular}


Table 12. Effect of age on the mitogenic response (net cpm) of the pantothenic acid diet groups. Values represent the mean net cpm derived from the sampling of 24 fish from each tank. $\div$ Diff represents the per cent increase in the net cpm between Play 19 and June 23, 1987 for each replicate. The mean increase and standard error of the mean for the pool of the semi-purified and Abernathy diet groups is shown.

\begin{tabular}{|c|c|c|c|c|c|c|c|}
\hline Tank & $5 / 19 / 87$ & $6 / 23 / 87$ & $\div$ Diff & Tank & $5 / 19 / 87$ & $6 / 23 / 87$ & $\%$ Diff \\
\hline $11 \mathrm{~A}$ & 938 & 5441 & 480 & $16 \mathrm{~A}$ & 4138 & 17541 & 324 \\
\hline $11 \mathrm{~B}$ & 928 & 2853 & 178 & $16 \mathrm{~B}$ & 4874 & 5481 & 12 \\
\hline $12 \mathrm{~A}$ & 1198 & 4963 & 314 & $17 \mathrm{~A}$ & 4529 & 16277 & 259 \\
\hline $12 B$ & 1435 & 3893 & 171 & $17 \mathrm{~B}$ & 4866 & $\mathrm{iA}$ & $\mathrm{NA}$ \\
\hline $13 A$ & 1151 & 5260 & 357 & $18 \mathrm{~A}$ & 2356 & 14256 & 503 \\
\hline $13 \mathrm{~B}$ & 1803 & 5153 & 376 & $18 \mathrm{~B}$ & 3256 & 5571 & 71 \\
\hline $14 \mathrm{~A}$ & 960 & 1433 & 49 & $19 \mathrm{~A}$ & 3354 & $\mathrm{IA}$ & NA \\
\hline $14 B$ & 351 & 8272 & 2256 & $19 B$ & 2408 & 15276 & 534 \\
\hline $15 \mathrm{~A}$ & 1034 & 9235 & 793.8 & $20 \mathrm{~A}$ & 3319 & 17230 & 351 \\
\hline $15 B$ & 441 & 6245 & 13163 & $20 B$ & 2351 & 16249 & 591 \\
\hline \multicolumn{6}{|c|}{ Nean $=629+215$} & \multicolumn{2}{|c|}{ Mean $=331+80$} \\
\hline
\end{tabular}


Table 13. Effect of age on the mitogenic response (stimulation index) of the pantothenic acid diet groups. Values represent the mean stimulation index derived from the sampling of 24 fish from each tank. 응 stimulation index between Nay 19 and June 23, 1987 for each replicate. The mean increase and standard error of the mean for the pool of the semi-purified and Abernathy diet groups is shown.

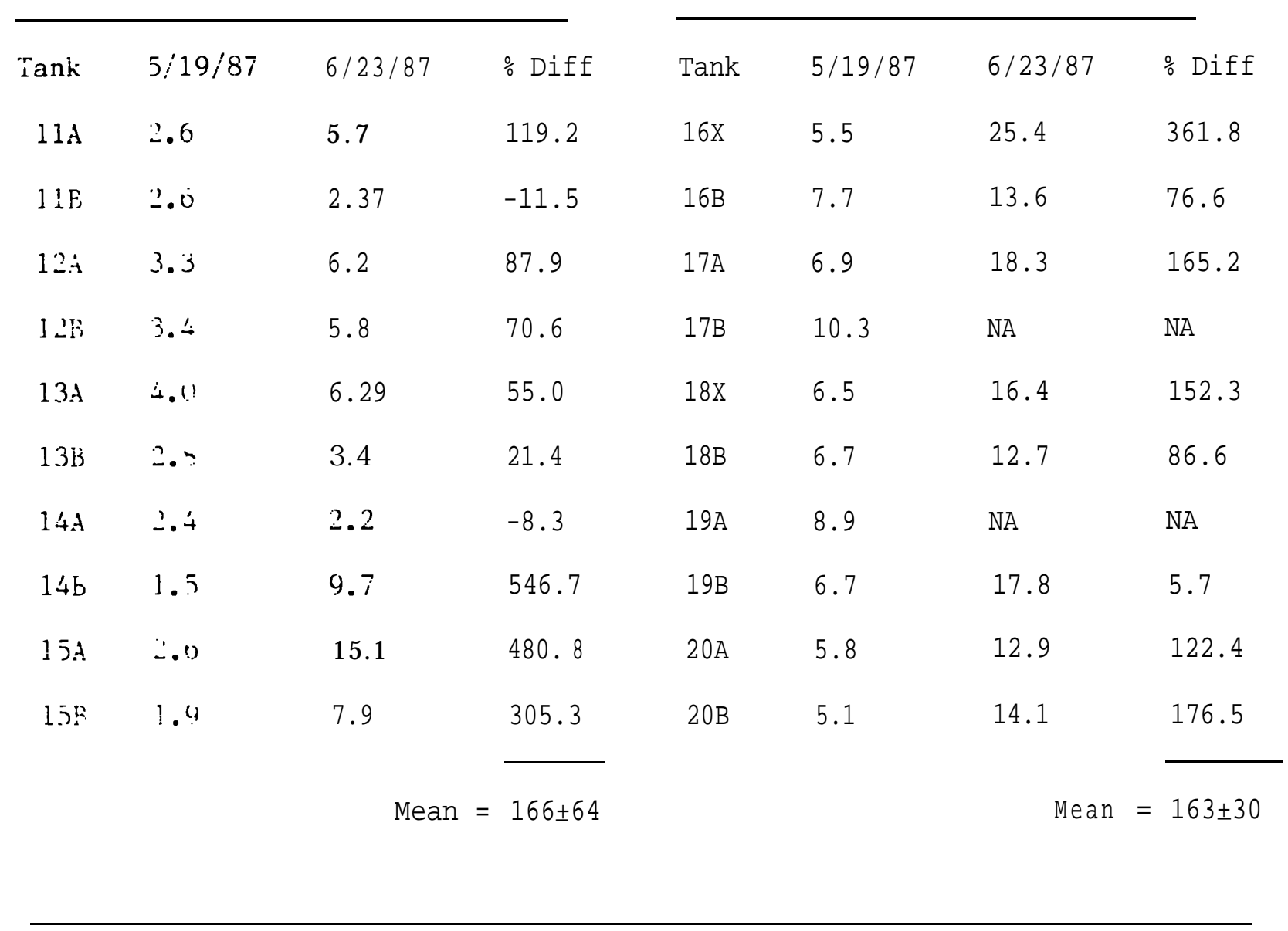


be the case in this study. It would also appear that the type of diet may play an important role in the development of these immune responses. In these particular studies, even though the weight differences (Table 14 and 15) at the time of assay are not dramatically different, dramatic differences in immune responsiveness occur. It may be that the generally higher growth rate and more efficient feed conversion with the Abernathy diet (Tabie 8) may be responsible for this difference within the riboflavin groups.

The reduction in the immune response to TSP-LPS could either indicate an absolute reduction in the number of lymphocytes responsive to this antigen, or alternatively, it could be due to an increase in the number of lymphocytes responsive to other antigens. In the latter case the number of PFC per $10^{6}$ lymphocytes would decrease, however the absolute number of T.PP-specific lymphocytes would remain the same. This possible sequence of events is quite likely since investigators examining the ontological development of immune specificities in mammals have noted that anti-TNP (or DNP) specificities are usually among the first to develop (Teale, 1985).

The differences between the riboflavin groups would indicate that the semi-purified diets cannot support continued development of the immune system to the degree that Abernathy diets can. At some point in time (in this case. approximately four months) fish fed semi-purified diet cease development of immune responsiveness.

Aeromonas salmonicida challenges

All challenges of diet groups with Aeromonas salmonicida revealed little dependence of survival on vitamin concentration with the possible exception of riboflavin incorporated into Abernathy diet (Fig. 19). In this 
Table 14. Average weights of fish in each riboflavin diet group at the time immunological testing. Each value represents the mean weight of $24 \mathrm{fish}$ sampled from each tank. The standard error of the mean is given.

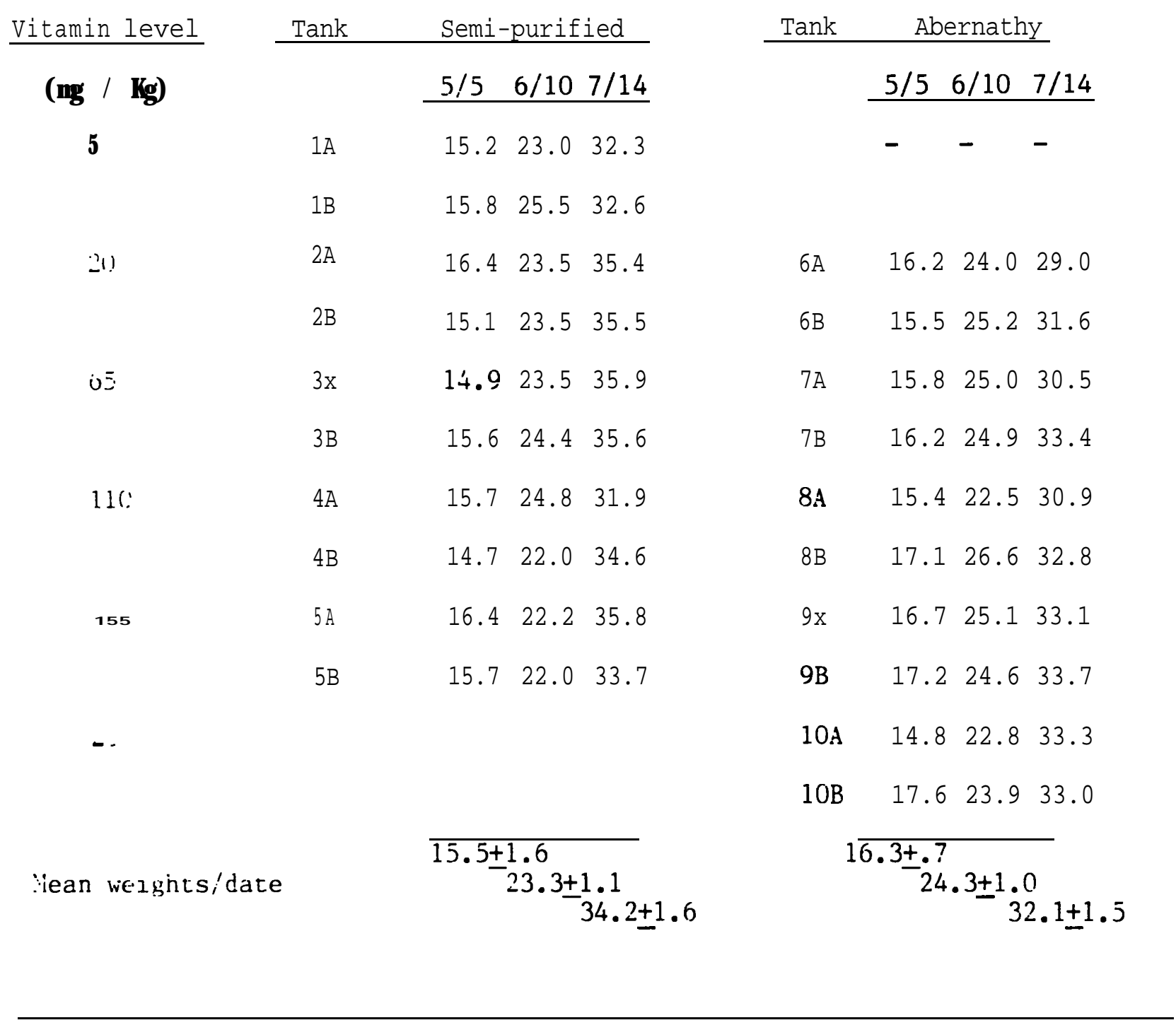


Table 15. Average weights of fish in each pantothenic acid diet group at the time of immunological testing. Each value represents the mean weight of 24 fish sampled from each tank. The standard error of the mean is given.

$\underline{\text { Vitamin level }}$

(mg / Kg)

10

40

130

220

310

Mean weights/date

400

Tank Semi-purified

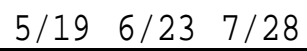

$\begin{array}{llll}11 a & 19.6 & 22.4 & 32.4\end{array}$

$\begin{array}{lll}18.3 & 27.0 & 32.4\end{array}$

$11 b$

$12 \mathrm{~A}$

$12 B$

$13 \mathrm{~A}$

$13 B$

$14 \mathrm{~A}$

$14 b$

$15 a$

$15 b$

$\begin{array}{lll}18.0 & 27.0 & 32.9\end{array}$

$18.6 \quad 24.7 \quad 32.9$

$18.3 \quad 24.6 \quad 29.0$

$\begin{array}{lll}18.1 & 23.8 & 32.5\end{array}$

$17.8 \quad 24.4 \quad 33.2$

$17.9 \quad 25.1 \quad 34.5$

$\begin{array}{lll}18.5 & 22.3 \quad 33.2\end{array}$

$18.0 \quad 23.5 \quad 31.9$

$8.3+.5$

$24.3+1.3$

$32.4+1.5$
Tank Abernathy

\begin{tabular}{lll}
$5 / 19 \quad 6 / 23 \quad 7 / 28$ \\
\hline
\end{tabular}

$\begin{array}{llll}16 \mathrm{~A} & 18.1 & 21.8 & 31.4\end{array}$

$\begin{array}{llll}\text { 16B } & 17.2 & 21.8 & 31.4\end{array}$

$\begin{array}{llll}17 \mathrm{~A} & 17.2 & 24.5 & 32.8\end{array}$

17B $\quad 17.5 \quad 25.4 \quad 33.6$

$\begin{array}{llll}18 a & 17.2 & 21.6 & 30.3\end{array}$

18B $\quad \begin{array}{llll}17.0 & 23.8 & 31.2\end{array}$

$\begin{array}{llll}19 a & 18.1 & 24.6 & 32.7\end{array}$

$\begin{array}{llll}19 b & 18.6 & 28.3 & 35.9\end{array}$

$20 \mathrm{~A} \quad 16.9 \quad 23.9 \quad 33.1$

20B $\quad \begin{array}{llll}18.2 & 22.3 \quad 31.2\end{array}$

$1 7 \longdiv { . 6 + . 6 }$ $24.2+1.9$

$32.6 \pm 1.6$ 


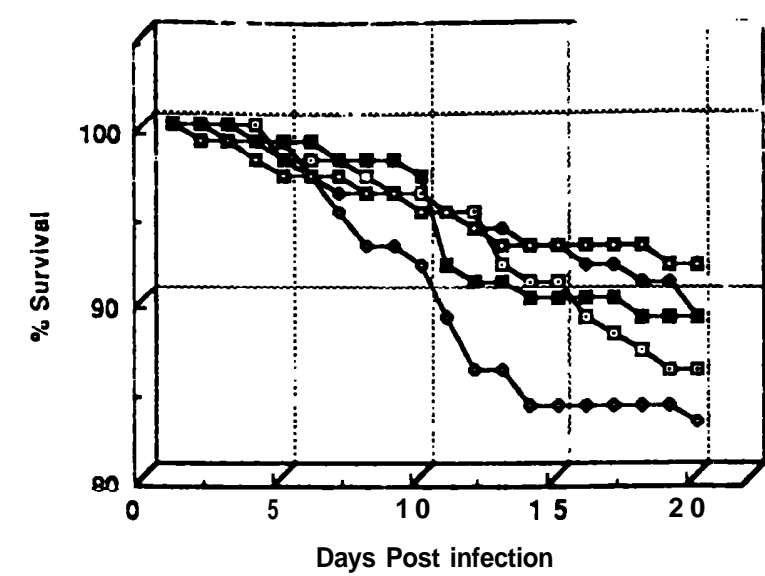

SemiourifiediRliboflavin

- $5 \mathrm{mg} / \mathrm{kg}$ diet

- 20 mgikg diet

$465 \mathrm{mg} / \mathrm{kg}$ diet

- 110 mgikg diet

- 155 mgikg diet

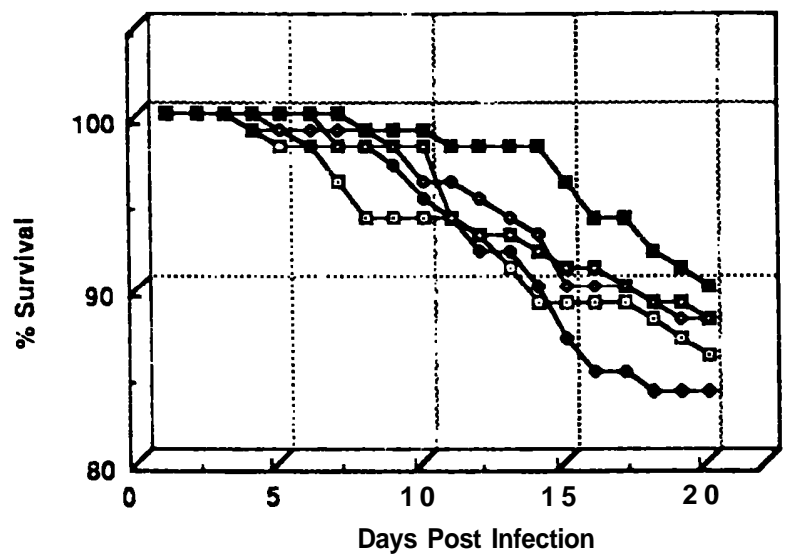

Abernathx. Aiboflavin

- 20 mglkg diet

$\sim 65$ mglkg diet

- $110 \mathrm{mg} / \mathrm{kg}$ diet

- 155 mgikg diet

- 200 mgikg diet

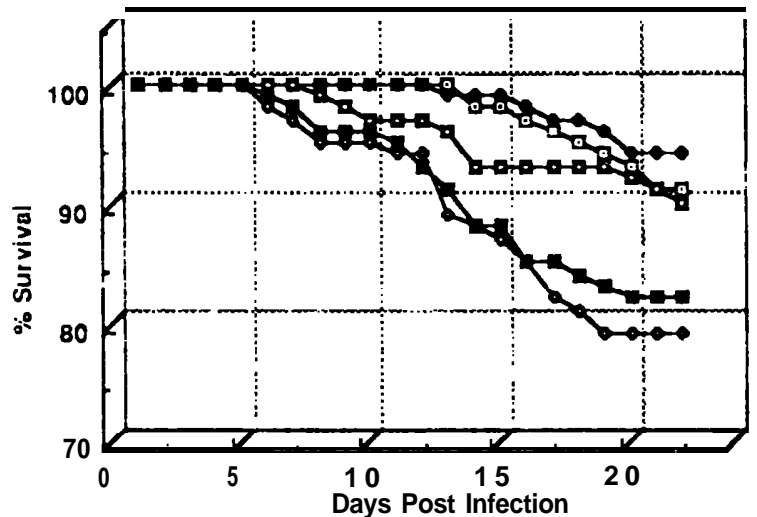

Semipuritied Pantothenic Acis

to- 10 mgikg diet

- $40 \mathrm{mg} / \mathrm{kg}$ diet

$4 \quad 130 \mathrm{mg} / \mathrm{kg}$ diet

- $220 \mathrm{mg} / \mathrm{kg}$ diet

- $310 \mathrm{mg} / \mathrm{kg}$ diet

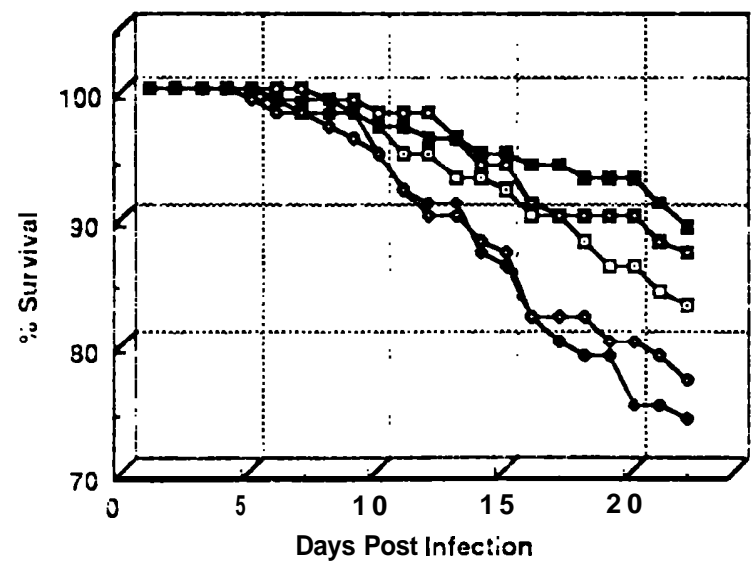

Abernathy Pantothenic Acid

-a- $40 \mathrm{mg} \cdot \mathrm{kg}$ diet

- $130 \mathrm{mg} \cdot \mathrm{kg}$ diet

- 220 mg.kg diet

- 310 mg.kg diet

$+400 \mathrm{mg} . \mathrm{kg}$ diet

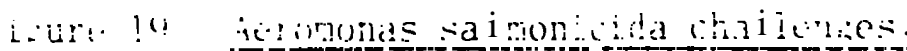

1: ; 
case, the per cent survival increases with increasing riboflavin. The semipurified diet with riboflavin, semi-purified with pantothenic acid, and Abernathy with pantothenic acid all demonstrated no consistent trend or correlation of survival with an increase or decrease of vitamin concentration. Examination of the mean time to death (MTD) after aeromonas salmonicida challenge again reveals no vitamin concentration-dependent difference (Tables 16 and 17). However, it is of interest to note that if all MTD values of the riboflavin / semi-purified replicates are averaged and compared to the aveage of all the riboflavin / Abernathy groups, an increase in the MTD is seen with the Abernathy groups (semi-purified $=10.9+1.4 \mathrm{vs}$. Abernathy $=14.5+2.9)$. This correlates well with what was seen in vitre. It appears that maintainence on Abernathy diet can enhance the ability of fish to withstand the Aeromonas challenge for a longer period of time. Thus the enhanced ability to generate an in vitro immune response correlates with enhanced resistance to a disease challenge. Such differences were not apparent in the pantothenic groups (Table 17), where the semipurified groups yielded a mean MTD of $14.9+2.3$ and the Abernathy groups gave a mean of 13.4+.3. Although both of these groups gave MTD values comparable to the riboflavin / Abernathy MTD, they are not directly comparable since the challenges for the pantothenic acid groups and riboflavin groups were conducted at different times 
Table 16. Per cent mortality and mean day to death for fish challenged with Aeromonas salmonicida. Fish were fed various levels of riboflavin in the semi-purified and Abernathy diets. Fifty fish were challenged per tank on 8/6/1987. The mean time to death expressed is the mean of the two replicates.

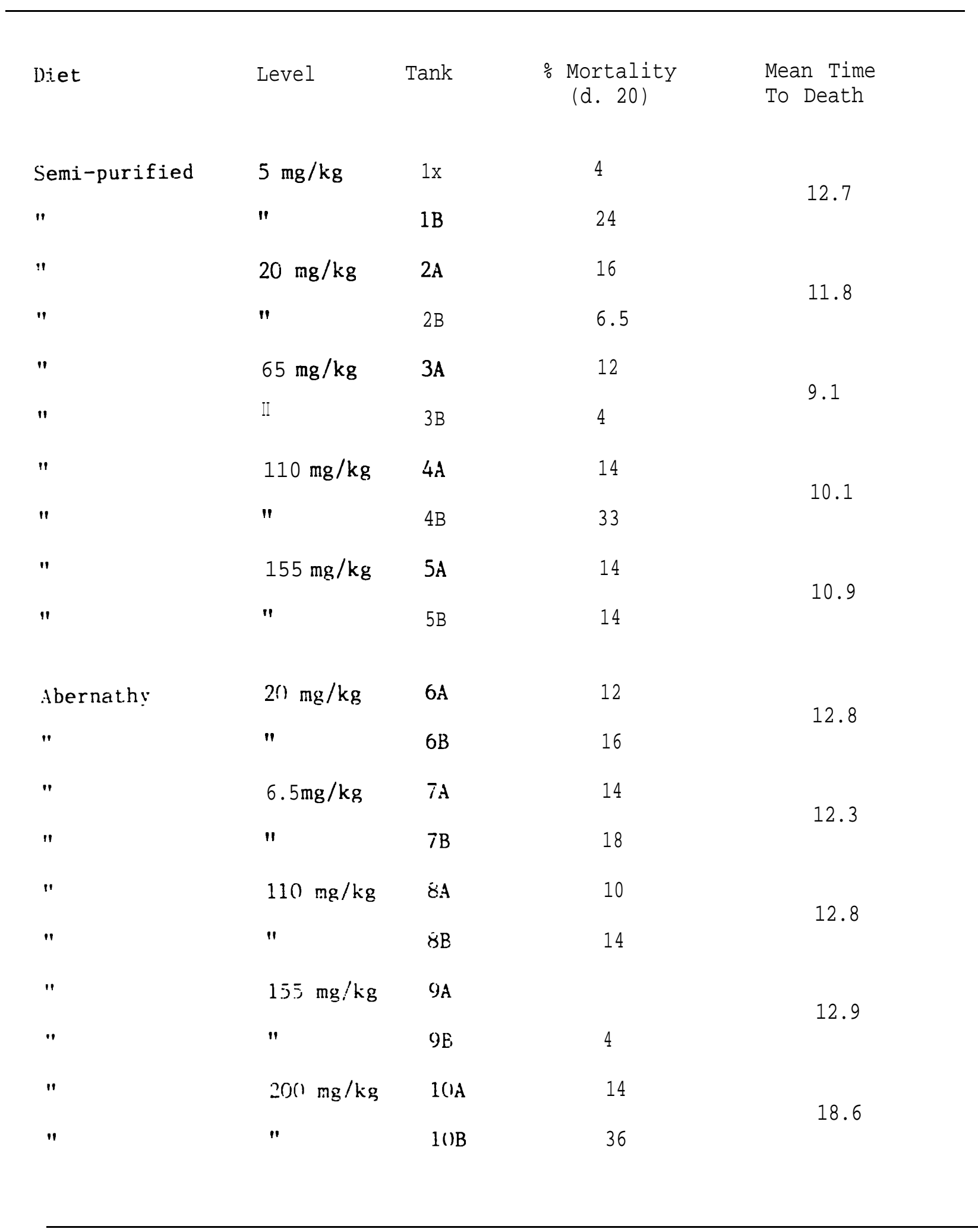


Table 17. Per cent mortality and mean day to death for fish challenged with Aeromonas salmonicida. Fish were fed various levels of pantothenic acid in the semi-purified and Abernathy diets. Fifty fish were challenged per tank on 8/201987. The mean time to death expressed is the mean of the two replicates.

\begin{tabular}{|c|c|c|c|c|}
\hline Diet & Level & Tank & $\begin{array}{l}\text { \% Mortality } \\
(\text { d. 20) }\end{array}$ & $\begin{array}{l}\text { Meamn Time } \\
\text { To Death }\end{array}$ \\
\hline Semi-purified & $10 \mathrm{mg} / \mathrm{kg}$ & $11 \mathrm{~A}$ & 10 & \multirow{2}{*}{17.6} \\
\hline$"$ & $"$ & $11 \mathrm{~B}$ & 4 & \\
\hline$"$ & $40 \mathrm{mg} / \mathrm{kg}$ & $12 \mathrm{~A}$ & 2 & \multirow{2}{*}{17.3} \\
\hline$"$ & $"$ & $12 \mathrm{~B}$ & 10 & \\
\hline$"$ & $130 \mathrm{mg} / \mathrm{kg}$ & $13 \mathrm{~A}$ & 12 & \multirow{2}{*}{13.3} \\
\hline$"$ & $"$ & $13 \mathrm{~B}$ & 4 & \\
\hline$"$ & $220 \mathrm{mg} / \mathrm{kg}$ & $14 \mathrm{~A}$ & 24 & \multirow{2}{*}{13.5} \\
\hline$"$ & $"$ & $14 B$ & 18 & \\
\hline$"$ & $310 \mathrm{mg} / \mathrm{kg}$ & $15 A$ & 14 & \multirow{2}{*}{12.7} \\
\hline$"$ & $"$ & $15 \mathrm{~B}$ & 22 & \\
\hline Abernathy & $40 \mathrm{mg} / \mathrm{kg}$ & $16 A$ & 16 & \multirow{2}{*}{13.6} \\
\hline$"$ & $"$ & $16 \mathrm{~B}$ & 12 & \\
\hline$"$ & $130 \mathrm{mg} / \mathrm{kg}$ & $17 \mathrm{~A}$ & 22 & \multirow{2}{*}{13.4} \\
\hline$"$ & $" 1$ & $17 \mathrm{~B}$ & 28 & \\
\hline & $220 \mathrm{mg} / \mathrm{kg}$ & $18 \mathrm{~A}$ & 12 & \multirow{2}{*}{13.6} \\
\hline & $"$ & $18 \mathrm{~B}$ & 8 & \\
\hline & 310 mg/kg & $19 \mathrm{~A}$ & 24 & \multirow{2}{*}{13.4} \\
\hline$"$ & $"$ & $19 \mathrm{~B}$ & 16 & \\
\hline$"$ & $400 \mathrm{mg} / \mathrm{kg}$ & $20 \mathrm{~A}$ & 3 & \multirow[t]{2}{*}{12.8} \\
\hline & $"$ & $20 B$ & 12 & \\
\hline
\end{tabular}


The primary goal in the third year of this project was to perform in vitro immunological assessments and disease challenges for fish maintained on various concentrations of riboflavin and panthothenic acid in Abernathy and Oregon test diets.

In these studies, it became apparent that no concentrations of either vitamin produced readily discernible differences in immune responsiveness. Thus it would appear that NRC riboflavin and pantothenic acid requirements for growth would be sufficient to insure a competent immune response. However, on the basis of these studies it can be concluded that the basic ration itself (i.e. Abernathy vs. Oregon test diet) may exert significant differences on the temporal development of immunocompetence, the overall magnitude of the immune response, and on the relative sensitivity of salmon to disease agents. On the basis of these experiments, it may be of benefit to examine all practical rations to determine their relative efficacy in generating competent immune systems in chinook salmon. 
1. Salaries (including personnel and benefits)

2. Travel and transportation (including per diem)

3. Ronexpendable equipment and material (greater than $\$ 1000$ per item)

4. Expendable equipment and material (sensitive in nature)

5. Operations and maintenance (including computer services and publications)

6. Overhead

7. The currently approved budget

8. Current budget period
$84-45 \mathrm{~A}$

$84-45 B$

$\$ 26492.28$

$\$ 41279.26$

368.83

5254.82

2429.58

3576.82

0.00

23847.58

17030.55

0.00

18014.42

24684.44

83870.00

113422.00

8/1/86-

$7 / 31 / 87$
8/1/86-

$9 / 30 / 87$ 
Almquist, H.J. and Grau, C.R. 1944. The amino acid requirements of the chick. J. Nurt. 28:325.

Avtalion, R.R. and Shahrabani, R. 1975. Studies on Phagocytosis. I. In vitre uptake and killing of living Staphyloccus aureus by peripheral leucocytes of carp (Cpprinus carpio). Immunology 29:1181.

Xxelrcd, A.E. and Traketellis, A.C. 1964. Relationship of pyridoxine to immunological phenomena. Pages 591-607 in R.W. Harris and I.G. Wool, editors. Vitamins and Hormones. Advances in Research and Applications.

Banks, Joe L., Taylor, W.G. and Leek, S. 1979. Carrying capacity recommendations for Olympia Area National Fish Hatcheries. U.S. Fish and Wildlife Service, Abernathy Salmon Cultural Development Center, Processed Report, 57 pp.

Banner, C.R., Rohovec, J.s.and Fryer, J.L. 1983. Renibacterium salmoninarum as a cause of mortality among chinook salmon in salt water. J. World, Maricul. Soc. 14:236.

Beisel, W.R. 1982. Single nutrients and Immunity. The American Journal of Clinical Nutrition 35(2): Feb. Supplement:417-468. Bell, G.R., Higgs, D.A., and Traxler, G.S. 1984. The effect of dietary ascorbate, zinc, and manganese on the development of experimentally induced bacterial kidney disease in sockeye salmon (Oncorhyncus nerka). Aquaculture 36(4): 293-311. Blalock, T.L., Thaxton, u... and Garlich, J.D. 1984. Humoral 
immunity in chicks experiencing marginal vitamin B-6 deficiency.

J. Nutr. $114(2): 312-322$.

Blazer, V.S. and Wolke, R.E. 1984. The effects of alpha-tocopherol on the immune response and non-specific resistance factors of rainbow trout (Salmo gairdneri Richardson). Aquaculture 37 (4):1-9.

Brett, J.R., Shelbourn, J.E. and Shoop, C.T. 1969. Growth rate and body composition of fingerling sockeye salmon, Oncorhynchus $\underline{\text { nerka, }}$ in relation to temperature and ration size. J. Fish. Res. Bd. Can. 26(9): 2363-2394.

Buterbaugh, G.L. and Willoughby, H. 1967. A feeding guide for brook, brown and rainbow trout. The Progressive Fish-Culturist 29: $210-215$.

Chatterjee, G.C. 1978. Nutrient deficiencies in animals: Vitamin C. Pages 149-176 in Miloslav Rechcigal, Jr., editor. Section E: Nutritional disorders, Volume II, Effects of Nutrient Deficiencies in Animals. CRC Handbook Series in Nutrition and Food. CRC Press, Inc., West Palm Beach, Florida.

Colnago, G.L., Jensen, L.S. and Long, P.L. 1984. Effect of selenium and vitamin $\mathrm{E}$ on the development of immunity to coccidiosis in chickens. Poultry Science 63(6): 1136-1143.

Cunningham, A. and Szenberg, A. 1968. Further improvements in the plaque technique for detecting single antibody-forming cells. Immunology 14:599.

Debes, S.X. and Kirskey, A. 1979. Influence of dietary pyridoxine on selected immune capacities of rat dams and pups. The Journal of Nurtrition 109: 744-759. 
Durve, V.S. and Lovell, R.T. 1982. Vitamin C and disease resistance in channel catfish (Icthiuruspunctatus). Can. J. Fish. Aquat. $\operatorname{sc} \pm 39(7): 848-951$.

Edwards, P.R. and Ewing, W.H. Identification of the Enterobacteriaciae. Burgess Publishing Co., Minneapolis, Minn., (1972).

Ellis, R.P. and Vorhies, M.W. 1976. Effects of supplemental dietary vitamin $E$ on the serological response of swine to an Escherichia coli bacterin. JAVMA 168:231-232.

Fowler, L.G. and Burrows, R.E. 1971. The Abernathy salmon diet. The Progressive Fish-Culturist 33: 67-75.

Getchell, R.G. 1983. Comparison of Renibacterium salmoninarum by antigenicanalysis, antimicrobial assay and growth. Master's Thesis. Corvllis, Oregon State University. 72 numb. leaves. Halver, J.E. 1972. The vitamins. Pages 29-103 in John E. Halver, editor. Fish Nutrition, Academic Press, Inc., New York, New York.

Hardy, R.W. 1979. Effect of dietary protein level on the pyridoxine requirement and disease resistance of chinook salmon. Pages 253-260 in Proceedings of the World Symposium on Finfish Nutritionand Fish Feed Technology, Vol. I, Hamburg, Germany, June 20-23, 1978.

Heinzerling, R.H., Nockels, C.F., Quarles, C.L. and Tengerdy, R.P. 1974. Protection of chicks against E. coli infection by dietary supplementation with vitamin E. Proceedings of the Society for Experimental Biology and Medicine 146:279-283. Horwithz, W., editor. 1980. Official methods of analysis of the 
Association of official Analytical Cheimisus. 13th edition.

Assoc. Off. Anal. Chem., Washington, D.C. : 1018 pp.

Hublou, W.F. and Jones, I.W. 1970. Fish Commission of Oregon hatchery production summaries, 1960-67 broods of fall chinook, spring chinook, coho and chum salmon and steelhead trout. Fish Commission of Oregon, Division of Fish Culture, Processed Report, $39 \mathrm{p}$.

Lee, D.J. and Sinnhuber, R.0. 1972. Lipid requirements. Pages 145180 in Fish Nutrition (J.E. Halver, editor. Fish Nutrition. Academic Press, Inc., New York, New York.

Li, J.C.R. 1964. Statistical inference. Edwards Brothers, Inc., Ann Arbor, Michigan. Vol. 1658 pp.

Mahnken, C.V.W., Spinelli, J. and Waknitz, F.W. 1980. Evaluation of an alkane yeast (Candida sp.) as a substitute for fish meal in Oregon moist rainbow trout (Salmo gairdneri). Aquaculture 20: McKinney, E.C., Ortiz, G., Lee, J.C., Sigel, M.M., Lopez, D.M. Epstein, R.S. and McLeod, T.F. 1976. Lymphocytes of fish: Multipotential or specialized? in Phylogeny of Thymus and Bone Marrow - Bursa Cells. Pages 73-82. Elsevier/North Holland Biomedical Press. Amsterdam, The Netherlands. $41-56$.

National Academy of Sciences. 1973. Number 11, Nutrient requirements of trout, salmon and catfish. Nutrient Requirements of Domestic Animals. Academy of Science, Washington, D.C.

Nelson, R.A. 1978. Effects of specific nutrient deficiences in 
animals: Pantothenic acid. Pages 59-63 in Miloslav

Rechcigal,Jr., editor. Section E: Nutritional Disorder, volume II., Effects of Nutrient Deficiences in Animals. CRC Handbook Series in Nutrition and Food. CRC Press, Inc., West Palm Beach Florida.

Nockels, C.R. 1980. The biological immune response - The effect of dietery vitamin E. Feedstuffs, June 16, pages, 22-23.

Oi, V.F. and Herzenberg, L.A. 1980. Immunoglobin-producing hybrid cell lines. In Selected Methods in Cellular Immunology.

(B. Mishell and S. Shiigi eds.) pp 297-302. W.H. Freeman and Co., San Francisco.

O'Leary, P.J. 1980. A partial characterization of high and low molecular weight immunoglobulin in rainbow trout (Salmo gairdneri) Doctoral Thesis. Covallis, Oregon State University. 72 numb. leaves.

Panda, B. and Combs, G.F. 1963. Impaired antibody production in chicks fed diets low in vitamin A, pantothenic acid or riboflavin. Proceedings of the Society for Experimental Biology and Medicine 113: 53-2-534.

Sanders, J.E. 1979. Ceil wall chemistry, deoxyribonucleic acid base composition and pathogenesis of the kidney disease bacterium in salmonid fishes. Ph.D. Thesis, Oregon State University, Corvallis, Oregon, 77p.

Scott, M.L., Nesheim, XC. and Young, R.J. 1976. Nutrition of the Chicken. M.L. Scott and Associates, Publishers, Ithaca, Sew York, $55 \mathrm{p}$. 
Sherwin, W.K., and Rowlands Jr., D.T. 1974. Development of humoral immunity in lethally irradiated mice reconstitued with fetal liver. J. Immunol. 11: 1353 .

Siddons, R.C. 1978. Nutrient deficiences in animals - folic acid. Pages 123-132. in Miloslav Rechcigal, Jr., editor. Section E: Nutritional Disorders, Volume II, Effects of Nutrient Deficiences in Animals. CRC Handbook Series in Nutrition and Food. CRC Press Inc., West Palm Beach, Florida.

Snedecor, G.W. and Cochran., W.G. 1971. Statistical Methods, 6th ed. Iowa State University Press, Ames., 593 pp.

Steffens, W. 1981. Protein utilization by rainbow trout (Salmo gairdneri) and carp (Cyprinus carpio): A brief review. Aquaculture 23: $337-345$.

Teale, J.M. 1985. B cell immune repertoire diversifies in a predictable temporal order in vitro. J. Immunol. 135: 954.

Torten, M.D., Johnson, R.C., Kaattari, S., Leung, C. and Benjamini, E. 1975. Immune plasma-dependent cytotoxicity of immune and nonimmune peripheral lpmphoid cells for target cells coated with bacterial outer unit membrane. Immunology 29: 1093.

Wedemeyer, G.A., Meyer, F.P. and Smith, L. 1976. Environmental Stress and Fish Diseases. In S.F. Snieszko and H.R. Axelrod, editors. Diseases of Fishes, Book 5. T.F.H. Publications, Inc., Neptune, New Jersey.

Wedemeyer, G.A. and Ross, A.J. 1973. Nutritional factors in the biochemical pathology of corynebacterial kidney disease in the coho salmon (Oncorhynchus kisutch) . Journal of the Fisheries 
Research Board of Canada 30: 296-298,

Wilgus, H.S. 1977. Disease, nutrition-interaction. Poultry Science 59:

Wood, J.W. 1974. Disease of Pacific salmon, their prevention and treatment. State of Washington Department of Fisheries, Hatchery Division, Olympia, Washington, $82 \mathrm{p}$. 